\title{
Healthcare's Sustainable Resource Planning Using Neutrosophic Goal Programming
}

\author{
Ibrahim M. Hezam $(\mathbb{D}$, Sarah A. H. Taher, Abdelaziz Foul, and Adel Fahad Alrasheedi $\mathbb{D}$ \\ Statistics \& Operations Research Department, College of Sciences, King Saud University, Riyadh, Saudi Arabia \\ Correspondence should be addressed to Ibrahim M. Hezam; ialmishnanah@ksu.edu.sa
}

Received 25 September 2021; Accepted 1 December 2021; Published 7 January 2022

Academic Editor: Mihajlo Jakovljevic

Copyright (C) 2022 Ibrahim M. Hezam et al. This is an open access article distributed under the Creative Commons Attribution License, which permits unrestricted use, distribution, and reproduction in any medium, provided the original work is properly cited.

\begin{abstract}
We develop neutrosophic goal programming models for sustainable resource planning in a healthcare organization. The neutrosophic approach can help examine the imprecise aspiration levels of resources. For deneutrosophication, the neutrosophic value is transformed into three intervals based on the truth, falsity, and indeterminacy-membership functions. Then, a crisp value is derived. Moreover, multi-choice goal programming is also used to get a crisp value. The proposed models seek to draw a strategic plan and long-term vision for a healthcare organization. Accordingly, the specific aims of the proposed flexible models are meant to evaluate hospital service performance and to establish an optimal plan to meet the growing patient needs. As a result, sustainability's economic and social goals will be achieved so that the total cost would be optimized, patients' waiting time would be reduced, high-quality services would be offered, and appropriate medical drugs would be provided. The simplicity and feasibility of the proposed models are validated using real data collected from the Al-Amal Center for Oncology, Aden, Yemen. The results obtained indicate the robustness of the proposed models, which would be valuable for planners who could guide healthcare staff in providing the necessary resources for optimal annual planning.
\end{abstract}

\section{Introduction}

Optimizing existing resources in health organizations is critical to meeting the needs of patients. At the same time, organizations must develop a future strategic plan of the existing resources commensurate with the predicted growth in the number of patients. Optimization approaches can support planning and decision-making at all levels. One of these approaches is goal programming in resources planning. Goal programming is a multi-objective optimization tool that helps a solution to move toward an ideal goal. In recent years, the use of goal programming has become more widespread, especially for analyzing and evaluating healthcare organizations. Numerous authors have considered goal programming to optimize the resources in health organizations. Parra et al. (1997) [1] proposed a goal programming model to evaluate the performance of a surgical service at a local general hospital. The authors aimed to improve the service under the available resources-for example, spatial occupation, staff availability, and financial support. Munoz et al. (2018) [2] improved a mathematical model based on goal programming to evaluate proposals in order to help in the selection of a mix of proposals. The main function of goal programming is the incorporation of strategic goals that support the vision and objectives of institutes. The model is applied using real data obtained from the Clinical and Translational Science Institute (CTSI) at Pennsylvania State University. Blake and Carter (2002) [3] proposed two linear goal programming models. The first model is used to determine case mix and volume for physicians under fixed service costs conditions. The second model addresses case-mix decisions as a commensurate set of practice changes for physicians. The trade-offs between case-mix and case costs are balanced using the proposed models and minimizing disturbance in order to preserve physician income. Rifai and Pecenka (1990) [4] applied goal programming to allocate resources in healthcare planning. Minimizing idle capacity and maximizing the profit are the main goals in this work. Kwak and Lee (2002) [5] proposed a multi-criteria mathematical programming model to evaluate 
strategic planning in a business process. This model is also based on goal programming. The goal levels are identified and prioritized using the analytic hierarchy process. Similarly, Lee and Kwak (1999) [6] presented a goal programming model for designing and evaluating effective information resource planning in a healthcare system. The proposed model addressed the multiple conflicting goals of a healthcare system and the multi-dimensional aspects of resource allocation planning. Also, the model allows flexibility of decision-making in resource allocation. The goals are decomposed and prioritized with respect to the corresponding criteria using the analytic hierarchy process. Grigoroudis and Phillis (2013) [7] proposed a nonlinear programming model to improve the health level of a population under several constraints. The system of systems approach is used to model the hierarchical structure of healthcare systems as well as for dynamic budget allocation for a national healthcare system in order to develop optimal policies. Lee and Kwak (2011) [8] developed a multi-criteria decision-making model for strategic enterprise resource planning adoption by considering both financial and nonfinancial business factors. Turgay and Taşkın (2015) [9] developed a fuzzy mixed goal programming model to optimize the healthcare organization's resource allocation problem in an uncertain environment.

The use of neutrosophic concept theory in goal programming was first introduced by Hezam et al. (2016) [10]. For more information on the works related to neutrosophic goal programming, see Munoz et al. (2018), Islam and Kundu (2018), Maiti et al. (2019), Sarma et al. (2019), Dey and Roy (2017), Pramanik and Banerjee (2018), and AlQuran and Hassan (2017) [2, 11-17].

At the same time, in conflict zones and poor communities, health organizations face difficulty meeting the population's needs [18]. There is an urgent need to provide excellent and comprehensive high-quality service for all patients under limited resources. In this regard, cancer is one of the most common diseases globally. Its treatment requires specialized experts, medical drugs, as well as exorbitant costs and time. In recent years, the number of people needing oncology services has increased significantly, especially in Yemen. Particularly, the country's growing population is facing health threats from the hazardous habit of chewing khat as well as pesticides used for growing the khat plant. The lack of health education, as well as early detection of tumors, also exacerbates the issue. Moreover, Yemen is a poor country that is suffering from ongoing conflicts. It has a dearth of human, material, and financial resources. Hence, the number of specialized oncology centers in Yemen is limited and, thus, does not meet the needs of oncology patients. As a result, most patients travel abroad for treatment. The Al-Amal Center for Oncology is one such specialized center for the treatment of tumors in Yemen. A large number of patients are treated by these health centers, which have limited resources. These complexities are reflected in the health facilities, making our data inaccurate, lacking, or ambiguous. Hence, we use the neutrosophic concept in this study.

In this article, we propose neutrosophic goal programming models for evaluating and optimizing the existing resources of health organizations and for optimal future planning. The main strategic goals to design the proposed models are (a) optimizing the center's resources; (b) matching the center service with the requirements of patients by providing high-quality services and appropriate medical drugs as well as reducing the waiting time; and (c) planning to meet the ideal center requirements by increasing the center capacity according to the predicted growth of patients. The real data are obtained from the Al-Amal Center for Oncology, Aden, Yemen. We use the data to validate the proposed models.

The remaining paper is organized as follows. Section 2 provides an overview of goal programming, dynamic goal programming, and multi-choice goal programming. Besides, it presents neutrosophic concepts and deneutrosophication. In Section 3, we formulate the proposed models, while a case study is presented in Section 4 . Section 5 reports the results and discussion, and then Section 6 concludes the study.

\section{Theory}

2.1. Goal Programming. Goal Programming is the most known method in multiple-criteria decision-making, proposed by Charnes and Cooper (1961). Goal programming is a generalization of linear programming that handles multiple conflicting objective measures, where a target is set for each measure to be achieved. The new objective function, or the "achievement function," seeks to minimize unwanted deviations from aspiration levels or a set of target values.

We can introduce two types of constraints in goal programming: hard and soft constraints. Hard constraints are the system constraints that cannot be violated (e.g., system resources and relational model constraints). In contrast, soft constraints are associated with prespecified targets. Both negative and positive deviational variables are added to these constraints and the undesired deviations are included in the objective function to be minimized.

The priority of goal programming is to satisfy the hard constraints before soft constraints. The preference structures to minimize the undesired deviations require different methods: preemptive, nonpreemptive, and Tchebycheff. The preemptive variant is used when there is a natural priority structure to the decision-maker(s) preferences, the nonpreemptive variant is used when each unwanted deviation has a relative weight (which can be equal), and Tchebycheff goal programming is used when the maximum deviation from the target is minimized.

Consider the following model:

$$
\begin{gathered}
z=\min \sum_{l=1}^{L} w_{l}\left(n_{l}+p_{l}\right), \\
f_{l}(x)+n_{l}-p_{l}=g_{l}, \quad \forall l \in L, \\
n_{l} \times p_{l}=0, \quad \forall l \in L, \\
A x \leq b,
\end{gathered}
$$




$$
\begin{aligned}
& x \geq 0, \quad n_{l}, \\
& p_{l} \geq 0, \quad \forall l \in L,
\end{aligned}
$$

where $g_{l}$ is specific goal of the objective function $f_{l}(x)$ $\forall l \in L . w_{l}$ is the penalty weight. $n_{l}$ and $p_{l}$ are the underand upper achievements of the $l^{\text {th }}$ goal, respectively. Equation (1) represents the objective function that minimizes the sum of the positive/negative deviations for each goal. Equation (2) is related to the decision-maker's goals and computes the respective positive and negative deviations from each goal. Equation (3) ensures that at least one of the deviations must be equal to zero. Equation (4) relates to the system constraints in the decision space. Equation (5) ensures that all decision variables are nonnegative.

2.2. Dynamic Goal Programming. Dynamic goal programming allows for a target value to be dynamic. This approach is used to evaluate along a planning period. References [19-21] addressed the dynamic goal programming where the target values are changed as per the planning period:

$$
\begin{aligned}
z & =\min \sum_{l=1}^{L} \sum_{t=1}^{T} w_{t}\left(n_{l p}+p_{l p}\right), \\
f_{l}(x)+n_{l t}-p_{l t} & =g_{l t}, \quad \forall l \in L, \quad \forall t \\
n_{l t} \times p_{l t} & =0, \quad \forall l \in L, \quad \forall t \in T, \\
A x & \leq b, \\
x & \geq 0, n_{l t}, \quad p_{l t} \geq 0, \quad \forall l \in L, \quad \forall t \in T,
\end{aligned}
$$

where $g_{l t}$ is specific goal of the objective function $f_{l}(x)$ $\forall l \in L$ per period $t$.

2.3. Multi-Choice Goal Programming. Multi-choice goal programming was proposed by Chang (2007) [22]. In this case, decision-makers are allowed to define multi-choice aspiration levels for each target. The decision-maker can use the multichoice model as a decision aid to make better decisions for a given problem. The mathematical model is as follows:

$$
\min \sum_{l=1}^{L} \mid f_{l}(x)-g_{l 1} \text { or } g_{l 2} \text { or } \ldots \text { or } g_{l m} \mid \text {. }
$$

Subject to

$$
X \in F(F \text { is a feasible set }) \text {. }
$$

Here, there are multi aspiration levels $\left(g_{l 1}\right.$ or $g_{l 2}$ or ... or $\left.g_{l m}\right)$. This model can be reformulated as:

$$
\begin{aligned}
\min n_{l}+p_{l}, & \\
f_{l}(x)+n_{l}-p_{l} & =\sum_{j=1}^{m} b_{l j} S_{l j}(B), \quad \forall l \in L, \\
S_{l j}(B) & \in R_{l}(x), \quad \forall l \in L, \\
n_{l t} \times p_{l t} & =0, \quad \forall l \in L, \quad \forall t \in T, \\
A x & \leq b, \quad \forall l \in L, \quad \forall t \in T, \\
x & \geq 0, n_{l t}, \quad p_{l t} \geq 0, \quad \forall l \in
\end{aligned}
$$

where $b_{l j}$ is the $j$ th aspiration level of the $l$ th goal and $S_{l j}(B)$ indicates the function of the binary serial number; $R_{l}(x)$ is the function of resources boundaries. For three aspiration levels, the first constraint of model (9) can be reformulated as the following constraints:

$$
\begin{aligned}
& f_{l}(x)+n_{l}-p_{l}= g_{l 1} b_{1} b_{2}+g_{l 2} b_{1}\left(1-b_{2}\right) \\
&+g_{l 3}\left(1-b_{1}\right) b_{2}, \\
& b_{1}+ b_{2}>0, \\
& b_{1}, b_{2} \in\{0,1\} .
\end{aligned}
$$

Constraint (10) makes at least $b_{1}$ or $b_{2}$ not equal zero. Therefore, only three choices $-g_{l 1}, g_{l 2}$, or $g_{l 3}$ - are yielded.

2.4. Neutrosophic Concept. In real applications, the uncertainty of the parameters is common in mathematical computations. Uncertainty arises owing to imprecise and inconsistent data. Zadeh proposed the fuzzy theory in 1965 to deal with these kinds of data [23]. However, fuzzy sets consider only the truth-membership function that is unable to efficiently represent accurate information. A new membership function, called falsity-membership function, was later developed by Atanassov (1986) [24], who introduced the intuitionistic fuzzy set. Nevertheless, this technique too was limited by drawbacks in decision-making. In 1998, Smarandache [25] introduced a new concept named "neutrosophic" that considers three memberships functions: truth, indeterminacy, and falsity.

\subsubsection{Neutrosophic Set}

Definition 1. Let $X \neq \varnothing$ be a universe set. A neutrosophic set $A$ in $X$ is characterized by a truth-membership function $\mu_{\sim^{N}}$, an indeterminacy-membership function $\sigma_{A^{N}}$, and a falsity-membership function $\nu_{A^{N}}$ : 


$$
\widetilde{A}^{N}=\left\{x, \mu_{A}(x), \sigma_{\widetilde{A}^{N}}(x), v_{\widetilde{A}^{N}}(x) ; \quad x \in X\right\},
$$

where $\left.\mu \sim_{\sim}: X \longrightarrow\right] 0^{-}, 1^{+}\left[, \quad \sigma_{\sim_{N}}: X \longrightarrow\right] 0^{-}, 1^{+}[$, and $\left.v_{\sim_{N}}: X \stackrel{A}{\longrightarrow}\right] 0^{-}, 1^{+}$[ represent the degrees of the truth-, indeterminacy-, and falsity-membership functions, respectively. No restriction exists on the sum of $\mu_{\sim_{N}}, \sigma_{\sim_{N}}$, and $\nu_{\sim_{N}}$. Thus, $0^{-} \leq \mu_{\widetilde{A}^{N}}(x)+\sigma_{\widetilde{A}^{N}}(x)+\nu_{\widetilde{A}^{N}}(x) \leq 3^{A_{+}}$for ${ }^{A} x \in X$

Definition 2. A set $(\alpha, \beta, \gamma)-$ cuts, generated by $\widetilde{A}^{N}$, where $\alpha, \beta, \gamma \in[0,1]$ are a fixed number such that $\alpha+\beta+\gamma \leq 3$ is defined as:

$$
\widetilde{A}_{\alpha, \beta, \gamma}^{N}= \begin{cases}\left\langle x, \mu_{\widetilde{A}^{N}}(x), \sigma_{\widetilde{A}^{N}}(x), v_{\widetilde{A}^{N}}(x)\right\rangle ; & x \in X, \\ \mu_{\widetilde{A}^{N}}(x) \geq \alpha, \sigma_{\widetilde{A}^{N}}(x) \leq \beta, v_{\widetilde{A}^{N}}(x) \leq \gamma ; & \alpha, \beta, \gamma \in[0,1],\end{cases}
$$

where $(\alpha, \beta, \gamma)-$ cuts, denoted by $\widetilde{A}_{\alpha, \beta, \gamma}^{N}$, is defined as the crisp set of elements $x$ that belong to $\widetilde{A}^{N}$ at least to the degree $\alpha$ and that belongs to $\widetilde{A}^{N}$ at most to the degree $\beta$ and $\gamma$.

2.4.2. Generalized Triangular Neutrosophic Number. A generalized triangular neutrosophic number $(\mathrm{GTNN}) \widetilde{\tau}_{a}^{N}=$ $\left(a, l_{\mu}, r_{\mu} ; w_{a}\right),\left(a, l_{\sigma}, r_{\sigma} ; u_{a}\right),\left(a, l_{\nu}, r_{\nu} ; y_{a}\right)$ is a special neutrosophic set on a real number set $\mathfrak{R}$ whose degree of truth, indeterminacy, and falsity are given by:

$$
\begin{aligned}
& \mu_{\tau_{a}^{N}}(x)= \begin{cases}\frac{x-a+l_{\mu}}{l_{\mu}} & a-l_{\mu} \leq x<a \\
w_{a} & x=a \\
\frac{a+r_{\mu}-x}{r_{\mu}} & a<x \leq a+r_{\mu} \\
0 & \text { otherwise }\end{cases} \\
& \sigma_{\widetilde{\tau}_{a}^{N}}(x)=\left\{\begin{array}{ll}
\frac{(a-x)+u_{a}\left(x-a+l_{\sigma}\right)}{l_{\sigma}} & a-l_{\sigma} \leq x<a \\
u_{a} & x=a \\
\frac{(x-a)+u_{a}\left(a+r_{\sigma}-x\right)}{r_{\sigma}} & a<x \leq a+r_{\sigma} \\
1 & \text { otherwise }
\end{array},\right. \\
& \nu_{\tau_{a}^{N}}(x)=\left\{\begin{array}{ll}
\frac{(a-x)+y_{a}\left(x-a+l_{\nu}\right)}{l_{\nu}} & a-l_{\nu} \leq x<a \\
y_{a} & x=a \\
\frac{(x-a)+y_{a}\left(a+r_{\nu}-x\right)}{r_{\nu}} & a<x \leq a+r_{\nu} \\
1 & \text { otherwise }
\end{array},\right.
\end{aligned}
$$


where $l_{\mu}, r_{\mu}, l_{\sigma}, r_{\sigma}, l_{\nu}$, and $r_{\nu}$ are called the spreads of the truth-, indeterminacy-, and falsity-membership functions, respectively; and $a$ is the mean value. $w_{a}$ represents the maximum degree of the truth-membership function, while $u_{a}$ and $y_{a}$ represent the minimum degrees of the indeterminacy- and falsity-membership functions, respectively, such that they satisfy the conditions below:

$$
\begin{aligned}
& 0 \leq w_{a} \leq 1, \\
& 0 \leq u_{a} \leq 1, \\
& 0 \leq y_{a} \leq 1, \\
& 0 \leq w_{a}+u_{a}+y_{a} \leq 3 .
\end{aligned}
$$

\subsection{3. $(\alpha, \beta, \gamma)-$ Cut Set of GTNN}

Definition 3. An $(\alpha, \beta, \gamma)-$ cut set of GTNN $\tilde{\tau}_{a}^{N}=\left(a, l_{\mu}, r_{\mu} ; w_{a}\right),\left(a, l_{\sigma}, r_{\sigma} ; u_{a}\right),\left(a, l_{\nu}, r_{\nu} ; y_{a}\right)$ is a crisp subset of $\mathfrak{R}$, which is defined as:

$$
\left(\widetilde{\tau}^{N}\right)_{a}^{\alpha, \beta, \gamma}=\left\{x: \mu_{\left(\widetilde{\tau}^{N}\right)_{a}}(x) \geq \alpha, \sigma_{\left(\widetilde{\tau}^{N}\right)_{a}}(x) \leq \beta, v_{\left(\widetilde{\tau}^{N}\right)_{a}}(x) \leq \gamma\right\},
$$

where

$$
0 \leq w_{a} \leq 1,0 \leq u_{a} \leq 1,0 \leq y_{a} \leq 1,
$$

and

$0 \leq w_{a}+u_{a}+y_{a} \leq 3$.

An $\alpha$-cut set of a GTNN $\tilde{\tau}_{a}^{N}$ is a crisp subset of $\mathfrak{R}$, which is defined as:

$$
\left(\tilde{\tau}^{N}\right)_{a}^{\alpha}=\left\{x: \mu_{\left(\tilde{\tau}^{N}\right)_{a}}(x) \geq \alpha\right\},
$$

where $0 \leq \alpha \leq w_{a}$.

According to the definition of GTNN, it can be easily shown that $\left(\widetilde{\tau}^{N}\right)_{a}^{\alpha}=\left\{x: \mu_{\left(\widetilde{\tau}^{N}\right)_{a}}(x) \geq \alpha,\right\}$ is a closed interval, defined by $\left(\tilde{\tau}^{N}\right)_{a}^{\alpha}=\left[a_{L}(\alpha), a_{R}(\alpha)\right]$ where $a_{L}(\alpha)=\left(a-l_{\mu_{a}}\right)$ $+\left(\alpha l_{\mu_{a}} / w_{a}\right)$ and $a_{R}(\alpha)=\left(a+r_{\mu_{a}}\right)-\left(\alpha r_{\mu_{a}} / w_{a}\right)$. The mean of $\left(\tilde{\tau}^{N}\right)_{a}^{\alpha}$ is

$$
a_{\text {mid }}(\alpha)=a+\frac{r_{\mu_{a}}-l_{\mu_{a}}}{2}\left[1-\frac{\alpha}{w_{a}}\right] .
$$

Similarly, a $\beta$ and $\gamma$-cut set of GTNN $\tilde{\tau}_{a}^{N}$ is a crisp subset of $\mathfrak{R}$, which is defined as

$$
\begin{aligned}
& \left(\widetilde{\tau}^{N}\right)_{a}^{\beta}=\left\{x: \sigma_{\left(\widetilde{\tau}^{N}\right)_{a}}(x) \leq \beta\right\}, \\
& \left(\widetilde{\tau}^{N}\right)_{a}^{\gamma}=\left\{x: v_{\left(\widetilde{\tau}^{N}\right)_{a}}(x) \leq \gamma\right\} .
\end{aligned}
$$

where $u_{a} \leq \beta \leq 1, y_{a} \leq \gamma \leq 1$

It follows from the definition that $\left(\tilde{\tau}^{N}\right)_{a}^{\beta}$ and $\left(\tilde{\tau}^{N}\right)_{a}^{\gamma}$ are closed intervals, denoted by $\left(\tilde{\tau}^{N}\right)_{a}^{\beta}=\left[a_{L}(\beta), a_{R}(\beta)\right]$ and $\left(\tilde{\tau}^{N}\right)_{a}^{\gamma}=\left[a_{L}(\gamma), a_{R}(\gamma)\right]$, which can be calculated as:

$$
\begin{aligned}
& a_{L}(\beta)=\left(a-l_{\sigma_{a}}\right)+\left((1-\beta) l_{\sigma_{a}} / 1-u_{a}\right) \\
& a_{R}(\beta)=\left(a+r_{\sigma_{a}}\right)-\left((1-\beta) r_{\sigma_{a}} / 1-u_{a}\right) \\
& a_{L}(\gamma)=\left(a-l_{v_{a}}\right)+\left((1-\gamma) l_{v_{a}} / 1-y_{a}\right) \\
& a_{R}(\gamma)=\left(a+r_{v_{a}}\right)-\left((1-\gamma) r_{v_{a}} / 1-y_{a}\right)
\end{aligned}
$$

Thus, the means of $\left(\widetilde{\tau}^{N}\right)_{a}^{\beta}$ and $\left(\tilde{\tau}^{N}\right)_{a}^{\gamma}$ are:

$$
\begin{aligned}
& a_{\text {mid }}(\beta)=a+\frac{r_{\sigma_{a}}-l_{\sigma_{a}}}{2}\left[\frac{\beta-u_{a}}{1-u_{a}}\right], \\
& a_{\text {mid }}(\gamma)=a+\frac{r_{v_{a}}-l_{v_{a}}}{2}\left[\frac{\gamma-y_{a}}{1-y_{a}}\right] .
\end{aligned}
$$

2.4.4. De-Neutrosophication. In this work, the neutrosophic parameters will be treatment using two methods. In the first method, the crisp value will be the average of the mean of the three intervals obtained from the $(\alpha, \beta, \gamma)$-cut set of GTNN. The crisp value can be calculated as equation (21).

$$
\begin{aligned}
\left(\tau^{N}\right)_{a}^{\alpha, \beta, \gamma}= & \frac{1}{3}\left(a_{\text {mid }}(\alpha)+a_{\text {mid }}(\beta)+a_{\text {mid }}(\gamma)\right), \\
= & a+\frac{r_{\mu_{a}}-l_{\mu_{a}}}{6}\left[1-\frac{\alpha}{w_{a}}\right],+\frac{r_{\sigma_{a}}-l_{\sigma_{a}}}{6}\left[\frac{\beta-u_{a}}{1-u_{a}}\right], \\
& +\frac{r_{v_{a}}-l_{v_{a}}}{6}\left[\frac{\gamma-y_{a}}{1-y_{a}}\right] .
\end{aligned}
$$

It can be easily proven that for $\tilde{\tau}_{a}^{N}=\left(a, l_{\mu}, r_{\mu} ; w_{a}\right)$, $\left(a, l_{\sigma}, r_{\sigma} ; u_{a}\right),\left(a, l_{\nu}, r_{\nu} ; y_{a}\right) \in \mathrm{GTNN}(\mathfrak{R})$ and for any $\alpha \in\left[0, w_{a}\right], \beta \in\left[u_{a}, 1\right], \gamma \in\left[y_{a}, 1\right]$, where $0 \leq \alpha+\beta+\gamma \leq 3$ :

$$
\left(\tilde{\tau}^{N}\right)_{a}^{\alpha, \beta, \gamma}=\left(\tilde{\tau}^{N}\right)_{a}^{\alpha} \wedge\left(\tilde{\tau}^{N}\right)_{a}^{\beta} \wedge\left(\tilde{\tau}^{N}\right)_{a}^{\gamma},
$$

where the symbol $\wedge$ denotes the minimum among $\left(\tilde{\tau}^{N}\right)_{a}^{\alpha},\left(\tilde{\tau}^{N}\right)_{a}^{\beta}$ and $\left(\tilde{\tau}^{N}\right)_{a}^{\gamma}$

Figure 1 illustrates the membership functions for a generalized triangular neutrosophic number (NN).

In the second method of the deneutrosophication, we employ multi-choice goal programming to select a crisp value in the three obtained intervals that led to the truth-, indeterminacy-, and falsity-membership functions $\left[a_{L}(\alpha), a_{R}(\alpha)\right],\left[a_{L}(\beta), a_{R}(\beta)\right]$, and $\left[a_{L}(\gamma), a_{R}(\gamma)\right]$, respectively. Thus, the multi-choice model will be employed to select one value from the three mean values that have been obtained using equations (17), (19) and (20).

\section{Proposed Models}

In this section, we formulate three goal programming models. First, we construct the basic goal programming model. We extend this model to include the neutrosophic concepts, whose parameters will be treated using the two methods in Section 2.4.4.

The nomenclature of the parameters and the variables we use herein are defined below:

Nomenclature

Sets:

$n=\{1,2, \ldots, n\}:$ Set of all the staff kinds, indexed by $i$; 


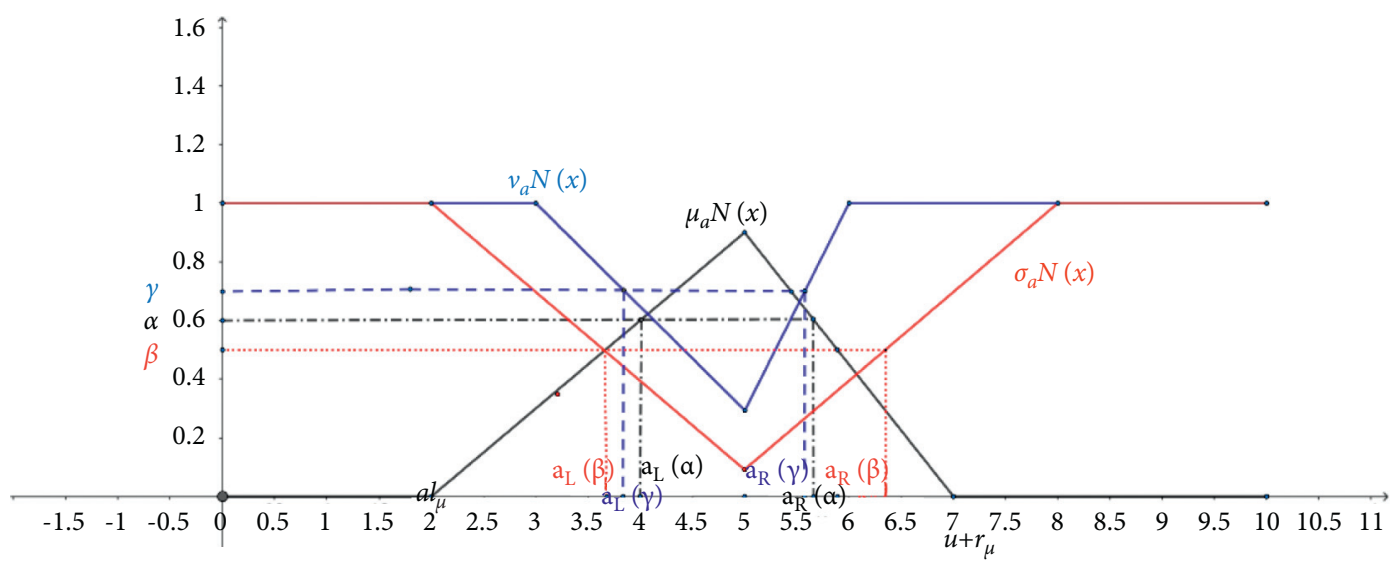

FIgURE 1: Graphical representation of membership functions for NN.

$m=\{1,2, \ldots, m\}$ : Set of all the medical device types, indexed by $j$;

$K=\{1,2, \ldots, K\}$ : Set of all the medical drug types, indexed by $k$.

Decision variables

$x_{i}$ : The number of $i$ staff;

$y_{j}$ : The number of $j$ medical devices;

$z_{k}$ : The number of $k$ medical drugs;

$p, n$ : The positive and the negative deviational variables; $p x_{i}, p y_{j}, p z_{k}$ : The positive deviational variables associated with the corresponding variable $i, j, k$;

$n x_{i}, n y_{j}, n z_{k}$ : The negative deviational variables associated with the corresponding variable $i, j, k$;

$\delta_{j} \in\{0,1\}: \quad$ A binary variable, where $\delta_{j}=\left\{\begin{array}{l}1 \text { if } y_{j}>(\mathrm{TNE})_{j} \\ 0 \text { if } y_{j} \leq(\mathrm{TNE})_{j}\end{array} \quad \forall j\right.$

$b_{r}$ : A binary variable $\forall r$;

$M$ : A large number.

Parameters

$c_{i}$ : The cost of $i$ staff;

$\mathrm{cm}_{j}$ : The cost of $j$ medical devices;

$c d_{k}$ : The cost of $k$ medical drugs;

$W_{l}$ : The weights of priority;

TB: The total budget;

TBS: The total budget for staff resources;

TBM: The total budget of the medical device resources;

TBD: The target budget of the medical drugs;

(TNS) $)_{\mathrm{i}}$ : The target number of $i$ staff;

(TNM) $)_{j}$ : The target number of the $j$ medical devices;

$(\mathrm{QD})_{\mathrm{k}}$ : The quantity demand of the $k$ medical drugs;

$\mathrm{SH}$ : The number of shifts;

$t$ : The number of years;

$\mathrm{XP}_{\text {day }}$ : The estimated number of the patients per day;

$(\mathrm{XR})_{\mathrm{i}}$ : The optimal ratio between the number of $i$ stuff and the patients;
$(\mathrm{YR})_{\mathrm{j}}$ : The optimal ratio between the number of $j$ medical device and the patients;

GR: The estimated growth rate of patients.

3.1. Goal Programming Model (GP). The goal programming model can be formulated as follows:

$$
\begin{aligned}
\min z= & \sum_{l=1}^{4}\left(p_{l}+n_{l}\right),+\sum_{i=1}^{n}\left(n x_{i}+p x_{i}\right), K \\
& +\sum_{j=1}^{m}\left(n y_{j}+p y_{j}\right),+\sum_{k=1}^{K}\left(n z_{k}+p z_{k}\right) .
\end{aligned}
$$

Subject to

$$
\begin{aligned}
& \sum_{i=1}^{n} c_{i} x_{i}+\sum_{j=1}^{m} c m_{j} y_{j}+\sum_{k=1}^{K} c d_{k} z_{k}+n_{1}-p_{1} \leq T B, \\
& \sum_{i=1}^{n} c_{i} x_{i}+n_{2}-p_{2} \leq \mathrm{TBS}, \\
& \sum_{j=1}^{m} c m_{j} y_{j}+n_{3}-p_{3} \leq \mathrm{TBM} \\
& \sum_{k=1}^{K} c d_{k} z_{k}+n_{4}-p_{4} \leq \mathrm{TBD} \\
& z_{k}+n z_{k}-p z_{k} \geq(\mathrm{QD})_{k} \quad \forall k, \\
& x_{i}+n x_{i}-p x_{i} \geq(\mathrm{TNS})_{i}, \\
& \forall i \text {, } \\
& y_{j}+n y_{j}-p y_{j} \geq(\mathrm{TNM})_{j}, \quad \forall j, \\
& y_{j}>(\mathrm{TNM})_{j}-\left(1-\delta_{j}\right) M \text {, } \\
& y_{j}<(\mathrm{TNM})_{j}+\delta_{j} M,
\end{aligned}
$$




$$
\mathrm{TBS}+c m_{j}-\left(1-\delta_{j}\right) M \leq \sum_{i=1}^{n} c_{i} x_{i} \leq \mathrm{TBS}+c m_{j}+\left(1-\delta_{j}\right) M
$$

$$
\begin{gathered}
\text { TBS }-\delta_{j} M \leq \sum_{i=1}^{n} c_{i} x_{i} \leq \mathrm{TBS}+\delta_{j} M, \\
x_{i}, y_{j}, z_{k} \in \mathbb{Z}^{+}, \quad \forall i, j, k .
\end{gathered}
$$

The objective function in equation (23) is to minimize unwished deviations from the targets. Unwished deviations in these models are the negative deviational variables. Positive deviations are also added to the objective function to avoid obtaining large, exaggerated deviations. This way, decision-makers can provide the obtained budgets. The constraint mentioned in equation (24) ensures that the total available budget is not exceeded. In the flexible model, the budget is dynamic, that is, it changes according to the annual growth rate of the number of patients. Thus, equation (36) is used to calculate the targeted total budget over $t$ number of years.

$$
\mathrm{TB}=\mathrm{TB}+t \times \mathrm{GR} \times \mathrm{TB} .
$$

As the number of patients increases with time, the total budget must be increased to cover all costs of the optimal staff, medical devices, and medical drugs that will optimally satisfy patients' demand. To achieve the maximum budget, that is, to attain the aspiration level total budget TB, the undesired variable $n_{1}$ must be minimized. Constraints (25)-(27), respectively, guarantee the sub-budgets for the staff, medical devices, and medical drugs each, such that they are not violated.

Similarly, in the flexible model, the sub-budgets change according to the growth of the number of patients. Thus, the dynamic sub-budgets of the staff, medical devices, and medical drugs change per year according to the following equations:

$$
\begin{aligned}
\mathrm{TBS} & =\mathrm{TBS}+t \times \mathrm{GR} \times \mathrm{TBS}, \\
\mathrm{TBM} & =\mathrm{TBM}+t \times \mathrm{GR} \times \mathrm{TBM}, \\
\mathrm{TBD} & =\mathrm{TBD}+t \times \mathrm{GR} \times \mathrm{TBD} .
\end{aligned}
$$

Constraint (28) allows for increasing the amount of the $k$ medical drug coinciding with the number of patients annually. In the same way, the amount of the $k$ medical drug will change with time based on the following dynamic equation:

$$
(\mathrm{QD})_{k}=(\mathrm{QD})_{k}+t \times \mathrm{GR} \times(\mathrm{QD})_{k} .
$$

Constraints (29) and (30) relate to the optimal ratio between the number of patients to the number of staff and medical devices. For example, the optimal ratio between the number of patients to number of oncologists for optimal care is about $1: 15$. On the other hand, the number of patients can be predicted from the previous data using the prediction techniques. Thus, we can estimate the number of patients daily. Therefore, the number of oncologists should be not less than

$$
x_{1} \geq(\mathrm{TNS})_{1}=\frac{\mathrm{SH}}{(\mathrm{XR})_{1}} \mathrm{XP}_{\mathrm{day}} .
$$

Similarly, for all other staff and medical advices that must be not less than the required number according to constraints (29) and (30), the target number of staff and medical devices can be calculated by the following equations:

$$
\begin{aligned}
(\mathrm{TNS})_{i} & =\frac{\mathrm{SH}}{(\mathrm{XR})_{i}} \mathrm{XP}_{\mathrm{day}}, \forall i \\
(\mathrm{TNM})_{j} & =\frac{\mathrm{SH}}{(\mathrm{YR})_{j}} \mathrm{XP}_{\mathrm{day}}, \forall j .
\end{aligned}
$$

We assume the importance of the availability of staff in the healthcare system and that medical devices have longterm durability. Therefore, constraints (31)-(34) transfers the surplus of the budget of the medical devices to the staff budget. This constraint investigates whether the medical device is available, and then shifts the budget of this type of device to the staff budget. Constraint (35) is related to the type of variables that must be integer variables.

3.2. Neutrosophic Goal Programming Model (NGP). The state of a country's economy can be expressed through its economic growth, stability, and stagnation. Thus, the total budget of any health center is affected by these economic states. Consequently, the sub-budgets will increase or decrease according to the economic state. Hence, the most suitable mathematical concept that expresses these states is the neutrosophic concept. In this subsection, we propose neutrosophic goal programming for healthcare planning. Three degrees are introduced in this case: acceptable, indeterminacy, and rejection.

The neutrosophic goal programming model is the extension of the goal programming model, where constraints (24)-(27) and (31)-(34) are rewritten as follows: 


$$
\begin{aligned}
& \sum_{i=1}^{n} c_{i} x_{i}+\sum_{j=1}^{m} c m_{j} y_{j}+\sum_{k=1}^{K} c d_{k} z_{k}+n_{1}-p_{1} \leq \widetilde{\mathrm{TB}}^{N} \\
& \sum_{i=1}^{n} c_{i} x_{i}+n_{2}-p_{2} \leq \widetilde{\mathrm{TBS}}^{N} \\
& \sum_{j=1}^{m} c m_{j} y_{j}+n_{3}-p_{3} \leq \widetilde{\mathrm{TBM}}^{N} \\
& \sum_{k=1}^{K} c d_{k} z_{k}+n_{4}-p_{4} \leq \widetilde{\mathrm{TBD}}^{N} \\
& y_{j}>(\mathrm{TNM})_{j}-\left(1-\delta_{j}\right) M, \\
& y_{j}<(\mathrm{TNM})_{j}+\delta_{j} M, \\
& (\widetilde{\mathrm{TBS}})^{N}+c m_{j}-\left(1-\delta_{j}\right) M \leq \sum_{i=1}^{n} c_{i} x_{i} \leq(\widetilde{\mathrm{TBS}})^{N}+c m_{j}+\left(1-\delta_{j}\right) M \text {, } \\
& (\widetilde{\mathrm{TBS}})^{N}-\delta_{j} M \leq \sum_{i=1}^{n} c_{i} x_{i} \leq(\widetilde{\mathrm{TBS}})^{N}+\delta_{j} M, \\
& \widetilde{\mathrm{TB}}^{N}=\left(\mathrm{TB}, l_{\mu}, r_{\mu} ; w_{\mathrm{TB}}\right),\left(\mathrm{TB}, l_{\sigma}, r_{\sigma} ; u_{\mathrm{TB}}\right),\left(\mathrm{TB}, l_{\nu}, r_{\nu} ; y_{\mathrm{TB}}\right) \text {, } \\
& \left.\left.(\widetilde{\mathrm{TBS}})^{N}=\left(\mathrm{TBS}, l_{\mu}, r_{\mu} ; w_{\mathrm{TBS}}\right) \text {, (TBS, } l_{\sigma}, r_{\sigma} ; u_{\mathrm{TBS}}\right) \text {, (TBS, } l_{\nu}, r_{\nu} ; y_{\mathrm{TBS}}\right) \text {, } \\
& \left.(\widetilde{\mathrm{TBM}})^{N}=\left(\mathrm{TBM}, l_{\mu}, r_{\mu} ; w_{\mathrm{TBM}}\right),\left(\mathrm{TBM}, l_{\sigma}, r_{\sigma} ; u_{\mathrm{TBM}}\right) \text {, (TBM, } l_{\nu}, r_{\nu} ; y_{\mathrm{TBM}}\right) \text {, } \\
& \widetilde{\mathrm{TBD}}^{N}=\left(\mathrm{TBD}, l_{\mu}, r_{\mu} ; w_{\mathrm{TBD}}\right),\left(\mathrm{TBD}, l_{\sigma}, r_{\sigma} ; u_{\mathrm{TBD}}\right),\left(\mathrm{TBD}, l_{\nu}, r_{\nu} ; y_{\mathrm{TBD}}\right) \text {, }
\end{aligned}
$$

where $(\widetilde{A})^{N}$ denotes the neutrosophic number defined using constraint (41).

3.3. Neutrosophic Multi-Choices Goal Programming Model (NMCGP). In this model, we use multi-choice goal programming to deal with values obtained from the neutrosophic set. Hence, constraints (24)-(27) are rewritten as follows:

$$
\begin{aligned}
& \sum_{i=1}^{n} c_{i} x_{i}+\sum_{j=1}^{m} c m_{j} y_{j}+ \sum_{k=1}^{K} c d_{k} z_{k}+n_{1}-p_{1} \leq \mathrm{TB}_{1}^{N} b_{1} b_{2}+\mathrm{TB}_{2}^{N} b_{1}\left(1-b_{2}\right)+\mathrm{TB}_{3}^{N}\left(1-b_{1}\right) b_{2}, \\
& \sum_{i=1}^{n} c_{i} x_{i}+n_{2}-p_{2} \leq \mathrm{TBS}_{1}^{N} b_{3} b_{4}+\mathrm{TBS}_{2}^{N} b_{3}\left(1-b_{4}\right)+\mathrm{TBS}_{3}^{N}\left(1-b_{3}\right) b_{4}, \\
& \sum_{j=1}^{m} c m_{j} y_{j}+n_{3}-p_{3} \leq \mathrm{TBM}_{1}^{N} b_{5} b_{6}+\mathrm{TBM}_{2}^{N} b_{5}\left(1-b_{6}\right)+\mathrm{TBM}_{3}^{N}\left(1-b_{5}\right) b_{6}, \\
& \sum_{k=1}^{K} c d_{k} z_{k}+n_{4}-p_{4} \leq \mathrm{TBD}_{1}^{N} b_{7} b_{8}+\mathrm{TBD}_{2}^{N} b_{7}\left(1-b_{8}\right)+\mathrm{TBD}_{3}^{N}\left(1-b_{7}\right) b_{8}, \\
& b_{r}+b_{r+1}>0, \\
& b_{r}, b_{r+1} \in\{0,1\}, \\
& r \in\{1,2, \ldots, 7\},
\end{aligned}
$$


where $\mathrm{TB}{ }_{1}^{N}, \mathrm{~TB}_{2}^{N}, \mathrm{~TB}_{3}^{N}, \mathrm{TBS}_{1}^{N}, \mathrm{TBS}_{2}^{N}, \mathrm{TBS}_{3}^{N}, \mathrm{TBM}_{1}^{N}$, $\mathrm{TBM}_{2}^{N}, \mathrm{TBM}_{3}^{N}, \mathrm{TBD}_{1}^{N}, \mathrm{TBD}_{2}^{N}$, and $\mathrm{TBD}_{3}^{N}$ can be obtained using equations (17), (19) and (20).

\section{Case Study}

For the case study, we collected and mined real data from the Al-Amal Center for Oncology in Aden, Yemen. Then, the number of patients was predicted daily, and the goals were set according to the predicted data.

The center was established in 2014 and covers an area of $50,000 \mathrm{~km}^{2}$. The center includes several departments and sections, such as outpatient clinics, inpatient section, laboratories and radiology department, early detection center, research center, intensive care, emergency section, a medical college, administrative, training, and staff housing.

Al-Amal is one of the few specialized centers for oncology in Yemen. Owing to the increasing rates of cancer, this center faces immense challenges in providing the necessary supplies for staff, medical devices, and medical drugs. Table 1 shows the increasing growth of the number of patients for the period between July 2015 and December 2017.

Based on the given data, the linear regression equation to predict the numbers of patients is XP $=1227+3526 t$, where $\mathrm{XP}$ is the estimated number of patients and $t$ is the number of years. Hence, the number of patients increases gradually with an average annual growth rate of $8 \%$. That is, the estimated number of patients on a working day is $\mathrm{XP}_{\text {day }} \cong 5+10 t$. Hence, the increasing number of patients daily under the existing budget requires more optimal use of resources. Moreover, we hope to increase the number of staffs, medical devices, and medical drugs as well, which would require increasing the budget. In the next step, increasing the total budget and sub-budgets would be a target, which would help meet the needs of growing patient numbers.

Table 2 shows the number of each kind of staff and the respective cost. The staff include oncologists, general doctors, radiologists, pharmacists, lab technicians, X-ray technicians, nurses, and other staff (other staff include remaining staff such as those in the administrative department).

Table 3 shows the number of each type of medical device and the respective cost. The medical devices include blood testing apparatus, chemistry apparatus, oncology indications, as well as ultrasonic, X-ray, mammogram, and other equipment (e.g., blood pressure- and blood sugar-testing devices as well as medical stethoscopes). Table 4 shows the list of the medical drugs, including their name, size, price, type, quantities used, and doses.

The existing budget of the center for the staff, medical devices, and medical drug are US $\$ 135,600$, US $\$ 45,260$, and US $\$ 390,000$, respectively, or US\$570,860 in total.

\section{Results and Discussion}

In this section, we implement the three proposed models using LINGO 18.0 software. We use these models for planning the sustainable development of the Al-Amal center for Oncology, Aden, Yemen. The proposed models would help decision-makers to plan optimality, as it allows us to determine the optimal number of required staffs, devices, and medical drugs for every period. The optimal ratio between the number of patients to the number of staff/medical devices/quantity of the medical drugs are assumed and the proposed models are applied to eight periods, from 2018 to 2048.

5.1. Results of the Goal Programming Model. The results of the first model are illustrated in Tables 5-10, where Table 5 shows the optimal budgets for each year and the ratio of each sub-budget of the total budget. Four budgets in this study are considered: total budget, staff budget, medical devices budget. and medical drugs budget. In the last column of this table, the growth rate for each budget is presented. The results indicate the need to increase the budget of the staff numbers, medical devices, and medical drugs by $13 \%, 6 \%$, $9 \%$, and $32 \%$, respectively, annually. Figure 2 illustrates the growth of the total budget as well as the other budgets.

Table 6 shows the optimal staff numbers that should be employed annually. Each row in this table indicates the years and the corresponding optimal staff number, each ratio of the total, and the corresponding cost for each. In the last row of this table, we observe an increase in the varying annual growth rates for each kind of staff, according to the corresponding optimal rate with respect to the number of patients. The growth rate for the total staff is $6 \%$.

Figure 3 illustrates the optimal number of different staffs. Evidently, the number of nurses increases the most with time. Similarly, Tables 7 and 8 show the increasing number of medical devices and medical drugs, respectively. Figure 4 illustrates the growth of the number of medical devices; we find that other equipment increases the most with time. The growth rate for the total number of medical devices is $4 \%$, which is less than the total number of staff growth owing to converted constraints (31)-(34).

Table 9 shows the negative deviational variables. Almost all variables equal to zero except $\mathrm{N} 1$ and $\mathrm{N} 4$, which are equal to US $\$ 4,800$. That is, in 2018, the optimal budget of the medical drugs must be decreased to US $\$ 385,200$. All the remaining negative deviations are equal to zero and, hence, there is no need to record them in the table. In contrast, the nonzero positive deviational variables are reported in Table 10.

We find that the total budgets, staff, and medical devices should be increased further in order to provide high-quality service in expectation of the annual increase in patients. The positive deviations of medical drugs are equal to zero-its dynamic budget can sufficiently cover needs.

\subsection{Results of the Neutrosophic Goal Programming Model.} There are three states of an economy: growth, stability, and stagnation. The budgets are assumed in accordance with these states. That is, the budgets are increased in the optimism state; are left unchanged or changed only marginally in the stability state; and are decreased in the pessimism state. This allows us to represent the budgets using the 
TABLe 1: Number of patients (7/2015-12/2017).

\begin{tabular}{lccccccccccccc}
\hline Months & JAN. & FEB. & MAR. & APR. & MAY & JUN. & JUL. & AUG. & SEP. & OCT. & NOV. & DEC. & Total \\
2015 & - & - & - & - & - & - & 263 & 277 & 278 & 296 & 334 & 361 & 1809 \\
2016 & 366 & 382 & 102 & 195 & 230 & 104 & 201 & 203 & 309 & 400 & 453 & 644 & 3589 \\
2017 & 650 & 681 & 689 & 696 & 730 & 733 & 737 & 755 & 770 & 788 & 794 & 838 & 8861 \\
\hline
\end{tabular}

TABLE 2: The number of staffs with corresponding costs.

\begin{tabular}{|c|c|c|c|c|c|c|c|c|c|}
\hline Staff & $\begin{array}{c}\quad x_{1} \\
\text { Oncologists }\end{array}$ & $\begin{array}{c}x_{2} \\
\text { General } \\
\text { doctors }\end{array}$ & $\begin{array}{c}x_{3} \\
\text { Radiologists }\end{array}$ & $\begin{array}{c}x_{4} \\
\text { Pharmacists }\end{array}$ & $\begin{array}{c}x_{5} \\
\text { Lab } \\
\text { technician }\end{array}$ & $\begin{array}{c}x_{6} \\
\text { X-ray } \\
\text { technician }\end{array}$ & $\begin{array}{c}x_{7} \\
\text { Nurses }\end{array}$ & $\begin{array}{c}x_{8} \\
\text { Other } \\
\text { staff }\end{array}$ & Total \\
\hline $\begin{array}{l}\text { Number of } \\
\text { staffs }\end{array}$ & 2 & 2 & 1 & 2 & 2 & 1 & 6 & 20 & 36 \\
\hline Cost $(\$)$ & 9600 & 3840 & 5760 & 3360 & 3360 & 3120 & 2400 & 3600 & \\
\hline Total cost $(\$)$ & 19200 & 7680 & 5760 & 6720 & 6720 & 3120 & 14400 & 72000 & 135600 \\
\hline$(\mathrm{XR})_{i}$ & 15 & 20 & 10 & 100 & 10 & 30 & 4 & 10 & \\
\hline
\end{tabular}

TABLE 3: The number of machines with corresponding costs.

\begin{tabular}{lccccccc}
\hline Machines & $\begin{array}{c}y_{1} \\
\text { Blood } \\
\text { Test }\end{array}$ & $\begin{array}{c}y_{2} \\
\text { Chemistry } \\
\text { apparatus }\end{array}$ & $\begin{array}{c}y_{3} \\
\text { Oncology } \\
\text { indications }\end{array}$ & $\begin{array}{c}y_{4} \\
\text { Ultrasonic }\end{array}$ & $\begin{array}{c}y_{5} \\
\text { X- } \\
\text { ray }\end{array}$ & $\begin{array}{c}y_{6} \\
\text { Mammogram }\end{array}$ & $\begin{array}{c}y_{7} \\
\text { Other } \\
\text { equipment }\end{array}$ \\
Number of & 1 & 1 & 1 & 1 & 1 & 1 & 200 \\
machines & 4200 & 4800 & 6660 & & 9600 & 206 \\
$\begin{array}{l}\text { Cost } \\
\text { Total cost }(\$)\end{array}$ & 4200 & 4800 & 6660 & 30 & 9600 & 2000 \\
$(\mathrm{YR})_{j}$ & 10 & 30 & 30 & 30 & 30 & 50 & 45260 \\
\hline
\end{tabular}

neutrosophic concept. Table 11 shows the values of the neutrosophic parameters. Then, equation (21) is used to give the deneutrosophic treatment to the obtained values.

Table 12 shows the optimal different budgets for each year. The results indicate that the budgets' growth rate is $15 \%$ annually. There is a marginal increase in the growth rate in the goal programming model. Table 13 shows that the optimal staff number should be determined yearly using this model. The growth rate for the total staff is $8 \%$. There is a small decrease in the growth rate in the goal programming model. In the same way, Tables 14 and 15 show the increase in medical devices and medical drugs. We find that other equipment increases the most with time. The negative deviational variables are also equal to zero except N3, which is equal US\$20,064 for 2018, as reported in Table 16. In contrast, the nonzero positive deviational variables are mentioned in Table 17.

5.3. Results of the Neutrosophic Multi-Choices Goal Programming Model. In this model, the multi-choice goal programming was applied to randomly select one value from the three values obtained from the neutrosophic membership functions. Table 18 shows the three means for each budget obtained using equations (17), (19) and (20) with the same parameters reported in Table 11.

Tables 19-22 show the obtained values for all variables. Similarly, Figures 5-7 illustrate the growth in the budgets, staff, medical devices, and medical drugs. Notably, we observe the aliasing of the curves, in contrast to Figure 2, indicating the random selection of the values of binary variable $b$ using multi-choice goal programming.

Overall, Table 23 summarizes the comparison between the three proposed models. The growth rates of the total budget and total staff numbers using the neutrosophic goal programming model were the highest, whereas the multichoice model shows the highest growth rate of the number of medical devices. The growth rate of medical drugs for all proposed models is almost equal. The multi-choice model yields the least deviations. We now discuss the results obtained in 2048 as an example. The total budget, total staff, and total medical devices obtained using the multi-choice model are higher than those obtained using the other models. Similarly, in the same year, the multi-choice model yields the lowest summation of deviations. Figures 8-10 illustrate a comparison between the proposed models for staff growth, the increasing medical devices, and the increase in the demand for medicines for the period between 2018 and 2048, respectively.

The case study shows that, in the three proposed models, the ratio of staff's budget to the total budget increases annually. In contrast, the ratio of the medical drugs' budget to the total budget decreases annually. Tables 5, 12, and 19 show that the ratios in 2018 are $28 \%, 34 \%$, and $15 \%$ of the staff's budget from the total budget and 64\%, 59\%, and 76\% of medical drugs' budget from the total budget, while the ratios in 2048 are $63 \%, 63 \%$, and $63 \%$ of the staff's budget from the total budget and $26 \%, 25 \%$, and $26 \%$ of medical drugs' budget from the total budget. The obtained results of the case study are almost similar. This convergence indicates the stability and robustness of the mathematical models. 
TABLE 4: Medical drug data.

\begin{tabular}{|c|c|c|c|c|c|c|}
\hline & Medical drug names & The size of the medicine $\left(\mathrm{cm}^{3}\right)$ & Drug Price $(\$)$ & Type of medication & Quantity 2016 & Dose of medication \\
\hline$z_{1}$ & Capecitabin & 243 & 1.18 & $\mathrm{Tab}$ & 13503 & $500 \mathrm{mg}$ \\
\hline$z_{2}$ & Cisplatin -1- & 128 & 1.67 & Vial & 80 & $10 \mathrm{mg}$ \\
\hline$z_{3}$ & Cisplatin -2- & 212.5 & 6.04 & Vial & 484 & $50 \mathrm{mg}$ \\
\hline$z_{4}$ & Cyclophosphamide -1- & 112 & 1.1 & Vial & 1061 & $500 \mathrm{mg}$ \\
\hline$z_{5}$ & Cyclophosphamide -2- & 54 & 0.7 & Vial & 1049 & $200 \mathrm{mg}$ \\
\hline$z_{6}$ & Cyclophosphamide-3- & 212.5 & 1.61 & Vail & 366 & $1000 \mathrm{mg}$ \\
\hline$z_{7}$ & Docitaxel -1- & 150 & 9.69 & Vial & 610 & $20 \mathrm{mg}$ \\
\hline$z_{8}$ & Docitaxel -2- & 282.6 & 18.98 & Vial & 694 & $80 \mathrm{mg}$ \\
\hline$z_{9}$ & Epirubicin -1- & 37.5 & 4.66 & Vial & 155 & $10 \mathrm{mg}$ \\
\hline$z_{10}$ & Epirubicin -2- & 112 & 18.7 & Vial & 605 & $50 \mathrm{mg}$ \\
\hline$z_{11}$ & Letrozole tabl. & 178.5 & 0.25 & Tab & 4535 & $2.5 \mathrm{mg}$ \\
\hline$z_{12}$ & Paclitaxel -1- & 128 & 31.45 & Vial & 210 & $150 \mathrm{mg}$ \\
\hline$z_{13}$ & Paclitaxel -2- & 68.25 & 14.8 & Vial & 275 & $100 \mathrm{mg}$ \\
\hline$z_{14}$ & Paclitaxel -3- & 54 & 6.66 & Vial & 155 & $30 \mathrm{mg}$ \\
\hline$z_{15}$ & Fluorouracil (5-fu)-1- & 200 & 0.66 & Vail & 110 & $250 \mathrm{mg}$ \\
\hline$z_{16}$ & Fluorouracil (5-fu)-2- & 262.5 & 1.38 & Vail & 226 & $500 \mathrm{mg}$ \\
\hline$z_{17}$ & Tamoxifen & 95 & 0.12 & $\mathrm{Tab}$ & 6374 & $20 \mathrm{mg}$ \\
\hline$z_{18}$ & Thalidomide & 80.325 & 1.35 & $\mathrm{Tab}$ & 778 & $100 \mathrm{mg}$ \\
\hline$z_{19}$ & Doxorubcin -1- & 91.875 & 5.26 & Vial & 490 & $50 \mathrm{mg}$ \\
\hline$z_{20}$ & Doxorubcin -2- & 58.5 & 1.66 & Vial & 756 & $10 \mathrm{mg}$ \\
\hline$z_{21}$ & Ifosphamid & 211.75 & 4.85 & Vial & 152 & $1000 \mathrm{mg}$ \\
\hline$z_{22}$ & Zoledronic acid & 58.5 & 15.82 & Vial & 213 & $4 \mathrm{mg}$ \\
\hline$z_{23}$ & Imatinib & 44 & 1.4 & $\mathrm{Tab}$ & 2575 & $400 \mathrm{mg}$ \\
\hline$z_{24}$ & Biclutamide & 33.8 & 0.82 & $\mathrm{Tab}$ & 2002 & $50 \mathrm{mg}$ \\
\hline$z_{25}$ & Carboplatin -1- & 212.5 & 35.7 & Vial & 281 & $450 \mathrm{mg}$ \\
\hline$z_{26}$ & Carboplatin -2- & 128 & 16.83 & Vial & 262 & $150 \mathrm{mg}$ \\
\hline$z_{27}$ & Gemcitabin -1- & 128 & 29.06 & Vial & 411 & $1000 \mathrm{mg}$ \\
\hline$z_{28}$ & Dacarbazin & 151.875 & 13.98 & Vail & 158 & $500 \mathrm{mg}$ \\
\hline$z_{29}$ & Pazopanib & 332.75 & 15.68 & Tab & 913 & $400 \mathrm{mg}$ \\
\hline$z_{30}$ & Irenotican & 45 & 16.92 & Vail & 110 & $40 \mathrm{mg}$ \\
\hline$z_{31}$ & Ca-folinat & 45 & 2.21 & Vial & 123 & $50 \mathrm{mg}$ \\
\hline$z_{32}$ & Mesna & 39 & 1.23 & Vial & 786 & $200 \mathrm{mg}$ \\
\hline$z_{33}$ & Vincristine -2- & 34.375 & 1.1 & Vial & 332 & $1 \mathrm{mg}$ \\
\hline$z_{34}$ & Etopside & 112 & 2 & Vail & 170 & $100 \mathrm{mg}$ \\
\hline$z_{35}$ & Bleomycin & 45 & 11.78 & Vial & 240 & $15 \mathrm{mg}$ \\
\hline$z_{36}$ & Vinblastin -1- & 58.5 & 5.7 & Vial & 286 & $10 \mathrm{mg}$ \\
\hline$z_{37}$ & Filgrastim 30U.i & 116 & 10.34 & Inj & 2108 & $10 \mathrm{mg}$ \\
\hline$z_{38}$ & Fludarabine & 126 & 68 & Vial & 41 & $50 \mathrm{mg}$ \\
\hline$z_{39}$ & Zoladex & 495 & 420 & Inj & 52 & $10.8 \mathrm{mg}$ \\
\hline$z_{40}$ & Liposomol Doxorubcin & 210 & 137.53 & Vial & 168 & $20 \mathrm{mg}$ \\
\hline
\end{tabular}

TABLe 5: The obtained budgets using GP model.

\begin{tabular}{|c|c|c|c|c|c|c|c|c|c|c|c|}
\hline \multicolumn{2}{|c|}{ Year } & \multirow{2}{*}{$\begin{array}{l}2018 \\
316705.7\end{array}$} & \multirow{2}{*}{$\begin{array}{l}2020 \\
426305.1\end{array}$} & \multirow{2}{*}{$\begin{array}{l}2024 \\
585093.9\end{array}$} & \multirow{2}{*}{$\begin{array}{l}2028 \\
920536.3\end{array}$} & \multirow{2}{*}{$\begin{array}{l}2032 \\
1263664\end{array}$} & \multirow{2}{*}{$\begin{array}{l}2036 \\
1586187\end{array}$} & \multirow{2}{*}{$\begin{array}{l}2040 \\
1921383\end{array}$} & \multirow{2}{*}{$\begin{array}{l}2044 \\
2258103\end{array}$} & \multirow{2}{*}{$\begin{array}{l}2048 \\
2580579\end{array}$} & \multirow{2}{*}{$\frac{\text { GR (\%) }}{13}$} \\
\hline TB & Cost & & & & & & & & & & \\
\hline \multirow{2}{*}{ TBS } & Cost & 87600 & 157440 & 259200 & 494640 & 720480 & 943200 & 1178640 & 1401120 & 1623840 & 6 \\
\hline & $(\%)$ & 28 & 37 & 44 & 54 & 57 & 59 & 61 & 62 & 63 & \\
\hline \multirow{2}{*}{ TBM } & Cost & 26000 & 32800 & 57400 & 92200 & 144800 & 179400 & 214200 & 263600 & 298200 & 9 \\
\hline & $(\%)$ & 8 & 8 & 10 & 10 & 11 & 11 & 11 & 12 & 12 & \\
\hline \multirow[t]{2}{*}{ TBD } & Cost & 203105.7 & 236065.1 & 268493.9 & 333696.3 & 398384.2 & 463587.2 & 528543.1 & 593383 & 658539.2 & 32 \\
\hline & $(\%)$ & 64 & 55 & 46 & 36 & 32 & 29 & 28 & 26 & 26 & \\
\hline
\end{tabular}

On the other hand, the large numbers, in this case, have made significant differences unclear. In general, the results obtained using both neutrosophic goal programming models are more realistic and flexible than the results obtained without the neutrosophic approach. We thus introduced several scenarios for each period, allowing the decision-maker more flexibility to choose the most appropriate model that corresponds to other uncontrolled factors in this study. For example, the economy grew rapidly in a specific period, which would enable the decision-maker to choose the largest budget then; the converse holds true during periods of recession. Therefore, the proposed models in this study provide sustainable planning for several future periods. 
TABLE 6: The number and corresponding cost of staff obtained using GP model.

\begin{tabular}{|c|c|c|c|c|c|c|c|c|c|c|}
\hline & Staff & $\begin{array}{c}\quad x_{1} \\
\text { Oncologists }\end{array}$ & $\begin{array}{c}x_{2} \\
\text { General } \\
\text { doctors }\end{array}$ & $\begin{array}{c}\quad x_{3} \\
\text { Radiologists }\end{array}$ & $\begin{array}{c}x_{4} \\
\text { Pharmacists }\end{array}$ & $\begin{array}{c}x_{5} \\
\text { Lab } \\
\text { technician }\end{array}$ & $\begin{array}{c}x_{6} \\
\text { X-ray } \\
\text { technician }\end{array}$ & $\begin{array}{c}x_{7} \\
\text { Nurses }\end{array}$ & $\begin{array}{c}x_{8} \\
\text { Other } \\
\text { staff }\end{array}$ & Total \\
\hline \multirow{3}{*}{2018} & No. & 2 & 2 & 3 & 2 & 3 & 2 & 4 & 3 & 21 \\
\hline & $\begin{array}{c}\text { Ratio } \\
(\%)\end{array}$ & 10 & 10 & 14 & 10 & 14 & 10 & 19 & 14 & 100 \\
\hline & Cost & 19200 & 7680 & 17280 & 6720 & 10080 & 6240 & 9600 & 10800 & 87600 \\
\hline \multirow{3}{*}{2020} & No. & 4 & 3 & 5 & 1 & 5 & 3 & 13 & 5 & 39 \\
\hline & $\begin{array}{c}\text { Ratio } \\
(\%)\end{array}$ & 10 & 8 & 13 & 3 & 13 & 8 & 33 & 13 & 100 \\
\hline & Cost & 38400 & 11520 & 28800 & 3360 & 16800 & 9360 & 31200 & 18000 & 157440 \\
\hline \multirow{3}{*}{2024} & No. & 6 & 5 & 9 & 1 & 9 & 3 & 23 & 9 & 65 \\
\hline & $\begin{array}{c}\text { Ratio } \\
(\%)\end{array}$ & 9 & 8 & 14 & 2 & 14 & 5 & 35 & 14 & 100 \\
\hline & Cost & 57600 & 19200 & 51840 & 3360 & 30240 & 9360 & 55200 & 32400 & 259200 \\
\hline \multirow{3}{*}{2028} & No. & 12 & 9 & 17 & 2 & 17 & 6 & 43 & 17 & 123 \\
\hline & $\begin{array}{c}\text { Ratio } \\
(\%)\end{array}$ & 10 & 7 & 14 & 2 & 14 & 5 & 35 & 14 & 100 \\
\hline & Cost & 115200 & 34560 & 97920 & 6720 & 57120 & 18720 & 103200 & 61200 & 494640 \\
\hline \multirow{3}{*}{2032} & No. & 17 & 13 & 25 & 3 & 25 & 9 & 63 & 25 & 180 \\
\hline & $\begin{array}{c}\text { Ratio } \\
(\%)\end{array}$ & 9 & 7 & 14 & 2 & 14 & 5 & 35 & 14 & 100 \\
\hline & Cost & 163200 & 49920 & 144000 & 10080 & 84000 & 28080 & 151200 & 90000 & 720480 \\
\hline \multirow{3}{*}{2036} & No. & 22 & 17 & 33 & 4 & 33 & 11 & 83 & 33 & 236 \\
\hline & $\begin{array}{c}\text { Ratio } \\
(\%)\end{array}$ & 9 & 7 & 14 & 2 & 14 & 5 & 35 & 14 & 100 \\
\hline & Cost & 211200 & 65280 & 190080 & 13440 & 110880 & 34320 & 199200 & 118800 & 943200 \\
\hline \multirow{3}{*}{2040} & No. & 28 & 21 & 41 & 5 & 41 & 14 & 103 & 41 & 294 \\
\hline & $\begin{array}{c}\text { Ratio } \\
(\%)\end{array}$ & 10 & 7 & 14 & 2 & 14 & 5 & 35 & 14 & 100 \\
\hline & Cost & 268800 & 80640 & 236160 & 16800 & 137760 & 43680 & 247200 & 147600 & 1178640 \\
\hline \multirow{3}{*}{2044} & No. & 33 & 25 & 49 & 5 & 49 & 17 & 123 & 49 & 350 \\
\hline & $\begin{array}{c}\text { Ratio } \\
(\%)\end{array}$ & 9 & 7 & 14 & 1 & 14 & 5 & 35 & 14 & 100 \\
\hline & Cost & 316800 & 96000 & 282240 & 16800 & 164640 & 53040 & 295200 & 176400 & 1401120 \\
\hline \multirow{3}{*}{2048} & No. & 38 & 29 & 57 & 6 & 57 & 19 & 143 & 57 & 406 \\
\hline & $\begin{array}{c}\text { Ratio } \\
(\%)\end{array}$ & 9 & 7 & 14 & 1 & 14 & 5 & 35 & 14 & 100 \\
\hline & Cost & 364800 & 111360 & 328320 & 20160 & 191520 & 59280 & 343200 & 205200 & 1623840 \\
\hline $\begin{array}{l}\text { GR } \\
(\%)\end{array}$ & 6 & 8 & 6 & 35 & 6 & 11 & 3 & 6 & 6 & \\
\hline
\end{tabular}

TABLE 7: The number with the corresponding cost of medical devices obtained using GP model.

\begin{tabular}{|c|c|c|c|c|c|c|c|c|c|}
\hline \multicolumn{2}{|c|}{ Medical devices } & \multirow{2}{*}{$\begin{array}{c}\begin{array}{c}y_{1} \\
\text { Blood test }\end{array} \\
1\end{array}$} & \multirow{2}{*}{$\begin{array}{c}y_{2} \\
\text { Chemistry apparatus } \\
1\end{array}$} & \multirow{2}{*}{$\begin{array}{c}y_{3} \\
\text { Oncology indications } \\
1\end{array}$} & \multirow{2}{*}{$\begin{array}{c}y_{4} \\
\text { Ultrasonic }\end{array}$} & \multirow{2}{*}{$\begin{array}{c}y_{5} \\
\text { X-ray } \\
1\end{array}$} & \multirow{2}{*}{$\begin{array}{c}y_{6} \\
\text { Mammogram }\end{array}$} & \multirow{2}{*}{$\begin{array}{c}y_{7} \\
\text { Other devices } \\
4\end{array}$} & \multirow{2}{*}{$\begin{array}{c}\text { Total } \\
10\end{array}$} \\
\hline \multirow{3}{*}{2018} & No. & & & & & & & & \\
\hline & Ratio (\%) & 10 & 10 & 10 & 10 & 10 & 10 & 40 & 100 \\
\hline & Cost & 4200 & 4800 & 6660 & 3200 & 3200 & 3200 & 800 & 26060 \\
\hline \multirow{3}{*}{2020} & No. & 2 & 1 & 1 & 1 & 1 & 1 & 17 & 24 \\
\hline & Ratio (\%) & 8 & 4 & 4 & 4 & 4 & 4 & 71 & 100 \\
\hline & Cost & 8400 & 4800 & 6660 & 3200 & 3200 & 3200 & 3400 & 32860 \\
\hline \multirow{3}{*}{2024} & No. & 3 & 2 & 2 & 2 & 2 & 1 & 30 & 42 \\
\hline & Ratio (\%) & 7 & 5 & 5 & 5 & 5 & 2 & 71 & 100 \\
\hline & Cost & 12600 & 9600 & 13320 & 6400 & 6400 & 3200 & 6000 & 57520 \\
\hline \multirow{3}{*}{2028} & No. & 5 & 3 & 3 & 3 & 3 & 2 & 57 & 76 \\
\hline & Ratio (\%) & 7 & 4 & 4 & 4 & 4 & 3 & 75 & 100 \\
\hline & Cost & 21000 & 14400 & 19980 & 9600 & 9600 & 6400 & 11400 & 92380 \\
\hline
\end{tabular}


TABle 7: Continued.

\begin{tabular}{|c|c|c|c|c|c|c|c|c|c|}
\hline \multicolumn{2}{|c|}{ Medical devices } & \multirow{2}{*}{$\begin{array}{c}y_{1} \\
\text { Blood test } \\
7\end{array}$} & \multirow{2}{*}{$\begin{array}{c}y_{2} \\
\text { Chemistry apparatus } \\
5\end{array}$} & \multirow{2}{*}{$\begin{array}{c}y_{3} \\
\text { Oncology indications } \\
5\end{array}$} & \multirow{2}{*}{$\begin{array}{c}y_{4} \\
\text { Ultrasonic } \\
5\end{array}$} & \multirow{2}{*}{$\begin{array}{c}y_{5} \\
\text { X-ray } \\
5\end{array}$} & \multirow{2}{*}{$\begin{array}{c}y_{6} \\
\text { Mammogram } \\
3\end{array}$} & \multirow{2}{*}{$\begin{array}{c}y_{7} \\
\text { Other devices } \\
84\end{array}$} & \multirow{2}{*}{$\begin{array}{c}\text { Total } \\
114\end{array}$} \\
\hline & No. & & & & & & & & \\
\hline \multirow[t]{3}{*}{2032} & Ratio (\%) & 6 & 4 & 4 & 4 & 4 & 3 & 74 & 100 \\
\hline & Cost & 29400 & 24000 & 33300 & 16000 & 16000 & 9600 & 16800 & 145100 \\
\hline & No. & 9 & 6 & 6 & 6 & 6 & 4 & 110 & 147 \\
\hline \multirow[t]{3}{*}{2036} & Ratio (\%) & 6 & 4 & 4 & 4 & 4 & 3 & 75 & 100 \\
\hline & Cost & 37800 & 28800 & 39960 & 19200 & 19200 & 12800 & 22000 & 179760 \\
\hline & No. & 11 & 7 & 7 & 7 & 7 & 5 & 137 & 181 \\
\hline \multirow[t]{3}{*}{2040} & Ratio (\%) & 6 & 4 & 4 & 4 & 4 & 3 & 76 & 100 \\
\hline & Cost & 46200 & 33600 & 46620 & 22400 & 22400 & 16000 & 27400 & 214620 \\
\hline & No. & 13 & 9 & 9 & 9 & 9 & 5 & 164 & 218 \\
\hline \multirow[t]{3}{*}{2044} & Ratio (\%) & 6 & 4 & 4 & 4 & 4 & 2 & 75 & 100 \\
\hline & Cost & 54600 & 43200 & 59940 & 28800 & 28800 & 16000 & 32800 & 264140 \\
\hline & No. & 15 & 10 & 10 & 10 & 10 & 6 & 190 & 251 \\
\hline \multirow[t]{2}{*}{2048} & Ratio (\%) & 6 & 4 & 4 & 4 & 4 & 2 & 76 & 100 \\
\hline & Cost & 63000 & 48000 & 66600 & 32000 & 32000 & 19200 & 38000 & 298800 \\
\hline GR (\%) & 7 & 11 & 11 & 11 & 11 & 18 & 2 & 4 & \\
\hline
\end{tabular}

TABLE 8: The quantities of medical drugs obtained using the GP model.

\begin{tabular}{|c|c|c|c|c|c|c|c|c|c|c|}
\hline Medical drug names & 2018 & 2020 & 2024 & 2028 & 2032 & 2036 & 2040 & 2044 & 2048 & GR (\%) \\
\hline$\overline{z_{1}}$ & 13503 & 15664 & 17824 & 22145 & 26466 & 30787 & 35108 & 39429 & 43750 & 32 \\
\hline$z_{2}$ & 80 & 93 & 106 & 132 & 157 & 183 & 208 & 234 & 260 & 32 \\
\hline$z_{3}$ & 484 & 562 & 639 & 794 & 949 & 1104 & 1259 & 1414 & 1569 & 32 \\
\hline$z_{4}$ & 1061 & 1231 & 1401 & 1741 & 2080 & 2420 & 2759 & 3099 & 3438 & 32 \\
\hline$z_{5}$ & 1049 & 1217 & 1385 & 1721 & 2057 & 2392 & 2728 & 3064 & 3399 & 32 \\
\hline$z_{6}$ & 366 & 425 & 484 & 601 & 718 & 835 & 952 & 1069 & 1186 & 32 \\
\hline$z_{7}$ & 610 & 708 & 806 & 1001 & 1196 & 1391 & 1586 & 1782 & 1977 & 32 \\
\hline$z_{8}$ & 694 & 806 & 917 & 1139 & 1361 & 1583 & 1805 & 2027 & 2249 & 32 \\
\hline$z_{9}$ & 155 & 180 & 205 & 255 & 304 & 354 & 403 & 453 & 503 & 32 \\
\hline$z_{10}$ & 605 & 702 & 799 & 993 & 1186 & 1380 & 1573 & 1767 & 1961 & 32 \\
\hline$z_{11}$ & 4535 & 5261 & 5987 & 7438 & 8889 & 10340 & 11791 & 13243 & 14694 & 32 \\
\hline$z_{12}$ & 210 & 244 & 278 & 345 & 412 & 479 & 546 & 614 & 681 & 32 \\
\hline$z_{13}$ & 275 & 319 & 363 & 451 & 539 & 627 & 715 & 803 & 891 & 32 \\
\hline$z_{14}$ & 155 & 180 & 205 & 255 & 304 & 354 & 403 & 453 & 503 & 32 \\
\hline$z_{15}$ & 110 & 128 & 146 & 181 & 216 & 251 & 286 & 322 & 357 & 32 \\
\hline$z_{16}$ & 226 & 263 & 299 & 371 & 443 & 516 & 588 & 660 & 733 & 32 \\
\hline$z_{17}$ & 6374 & 7394 & 8414 & 10454 & 12494 & 14533 & 16573 & 18613 & 20652 & 32 \\
\hline$z_{18}$ & 778 & 903 & 1027 & 1276 & 1525 & 1774 & 2023 & 2272 & 2521 & 32 \\
\hline$z_{19}$ & 790 & 917 & 1043 & 1296 & 1549 & 1802 & 2054 & 2307 & 2560 & 32 \\
\hline$z_{20}$ & 756 & 877 & 998 & 1240 & 1482 & 1724 & 1966 & 2208 & 2450 & 32 \\
\hline$z_{21}$ & 152 & 177 & 201 & 250 & 298 & 347 & 396 & 444 & 493 & 32 \\
\hline$z_{22}$ & 213 & 248 & 282 & 350 & 418 & 486 & 554 & 622 & 691 & 32 \\
\hline$z_{23}$ & 2575 & 2987 & 3399 & 4223 & 5047 & 5871 & 6695 & 7519 & 8343 & 32 \\
\hline$z_{24}^{20}$ & 2002 & 2323 & 2643 & 3284 & 3924 & 4565 & 5206 & 5846 & 6487 & 32 \\
\hline$z_{25}$ & 281 & 326 & 371 & 461 & 551 & 641 & 731 & 821 & 911 & 32 \\
\hline$z_{26}$ & 262 & 304 & 346 & 430 & 514 & 598 & 682 & 766 & 849 & 32 \\
\hline$z_{27}$ & 411 & 477 & 543 & 675 & 806 & 938 & 1069 & 1201 & 1332 & 32 \\
\hline$z_{28}$ & 158 & 184 & 209 & 260 & 310 & 361 & 411 & 462 & 512 & 32 \\
\hline$z_{29}$ & 913 & 1060 & 1206 & 1498 & 1790 & 2082 & 2374 & 2666 & 2959 & 32 \\
\hline$z_{30}$ & 110 & 128 & 146 & 181 & 216 & 251 & 286 & 322 & 357 & 32 \\
\hline$z_{31}$ & 123 & 143 & 163 & 202 & 242 & 281 & 320 & 360 & 399 & 32 \\
\hline$z_{32}$ & 786 & 912 & 1038 & 1290 & 1541 & 1793 & 2044 & 2296 & 2547 & 32 \\
\hline$z_{33}$ & 332 & 386 & 439 & 545 & 651 & 757 & 864 & 970 & 1076 & 32 \\
\hline$z_{34}$ & 170 & 198 & 225 & 279 & 334 & 388 & 442 & 497 & 551 & 32 \\
\hline$z_{35}$ & 240 & 279 & 317 & 394 & 471 & 548 & 624 & 701 & 778 & 32 \\
\hline$z_{36}$ & 286 & 332 & 378 & 470 & 561 & 653 & 744 & 836 & 927 & 32 \\
\hline$z_{37}$ & 2108 & 2446 & 2783 & 3458 & 4132 & 4807 & 5481 & 6156 & 6830 & 32 \\
\hline$z_{38}$ & 41 & 48 & 55 & 68 & 81 & 94 & 107 & 120 & 133 & 32 \\
\hline$z_{39}$ & 52 & 61 & 69 & 86 & 102 & 119 & 136 & 152 & 169 & 32 \\
\hline$z_{40}$ & 168 & 195 & 222 & 276 & 330 & 384 & 437 & 491 & 545 & 32 \\
\hline Sum & 44199 & 51288 & 58361 & 72509 & 86646 & 100793 & 114929 & 129081 & 143223 & 32 \\
\hline
\end{tabular}


TABLE 9: The negative deviational variables obtained using GP model.

\begin{tabular}{lccccccccc}
\hline Negative deviations & 2018 & 2020 & 2024 & 2028 & 2032 & 2036 & 2040 & 2044 & 2048 \\
\hline N1 & 48000 & 0 & 0 & 0 & 0 & 0 & 0 & 0 \\
N2 & 0 & 0 & 0 & 0 & 0 & 0 & 0 & 0 \\
N3 & 0 & 0 & 0.2 & 0 & 0 & 0 & 0 & 0 \\
N4 & 48000 & 0 & 0 & 0 & 0 & 0 & 0 & 0 \\
\hline
\end{tabular}

TABle 10: The positive deviational variables obtained using the GP model.

\begin{tabular}{lccccccccc}
\hline Positive deviations & 2018 & 2020 & 2024 & 2028 & 2032 & 2036 & 2040 & 2044 & 2048 \\
\hline P1 & 0 & 288 & 160415.8 & 562485.6 & 965498.4 & 1344271 & 1755267 & 2148461 & 2527308 \\
P2 & 0 & 144 & 80208 & 272256 & 454704 & 634032 & 826080 & 1005168 & 1184496 \\
P3 & 0 & 0 & 0 & 17973.6 & 56090.4 & 76207.2 & 103107.3 & 138125.4 & 158316.4 \\
P4 & 0 & 144 & 80208 & 272256 & 454704 & 634032 & 826080 & 1005168 & 1184496 \\
PX1 & 1.333333 & 0.666667 & 0 & 0.666667 & 0.333333 & 0 & 0.666667 & 0.333333 & 0 \\
PX2 & 1.5 & 0.5 & 0.5 & 0.5 & 0.5 & 0.5 & 0.5 & 0.5 & 0.5 \\
PX3 & 2 & 0 & 0 & 0 & 0 & 0 & 0 & 0 & 0 \\
PX4 & 1.9 & 0.5 & 0.1 & 0.3 & 0.5 & 0.7 & 0.9 & 0.1 & 0.3 \\
PX5 & 2 & 0 & 0 & 0 & 0 & 0 & 0 & 0 \\
PX6 & 1.666667 & 1.333333 & 0 & 0.333333 & 0.666667 & 0 & 0.333333 & 0.666667 \\
PX7 & 1.5 & 0.5 & 0.5 & 0.5 & 0.5 & 0.5 & 0.5 & 0.5 \\
PX8 & 2 & 0 & 0 & 0 & 0 & 0 & 0 & 0 \\
PY1 & 0.75 & 0.75 & 0.75 & 0.75 & 0.75 & 0.75 & 0.75 & 0.75 \\
PY2 & 0.833333 & 0.166667 & 0.5 & 0.166667 & 0.833333 & 0.5 & 0.166667 & 0.833333 \\
PY3 & 0.833333 & 0.166667 & 0.5 & 0.166667 & 0.833333 & 0.5 & 0.166667 & 0.833333 \\
PY4 & 0.833333 & 0.166667 & 0.5 & 0.166667 & 0.833333 & 0.5 & 0.166667 & 0.833333 \\
PY5 & 0.833333 & 0.166667 & 0.5 & 0.166667 & 0.833333 & 0.5 & 0.166667 & 0.833333 & 0.5 \\
PY6 & 0.9 & 0.5 & 0.1 & 0.3 & 0.5 & 0.7 & 0.5 & 0.5 \\
PY7 & 0.666667 & 0.333333 & 0 & 0.333333 & 0.666667 & 0 & 0.333333 & 0.666667 & 0.5 \\
\hline
\end{tabular}

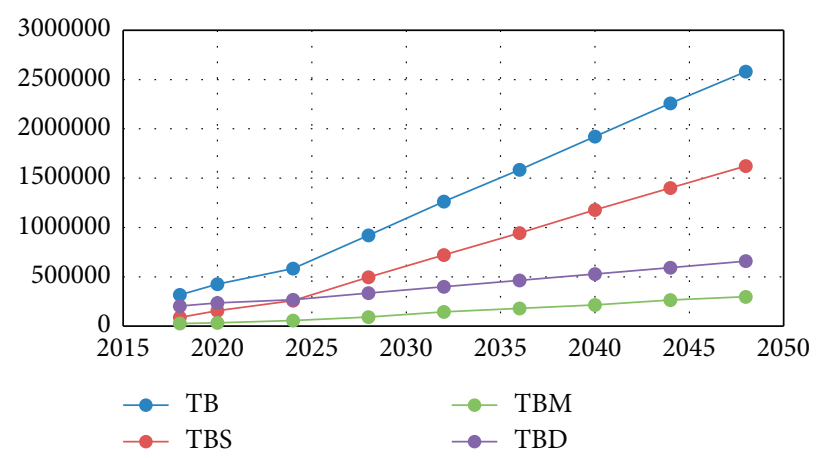

FIGURE 2: Budget growth using the GP model.

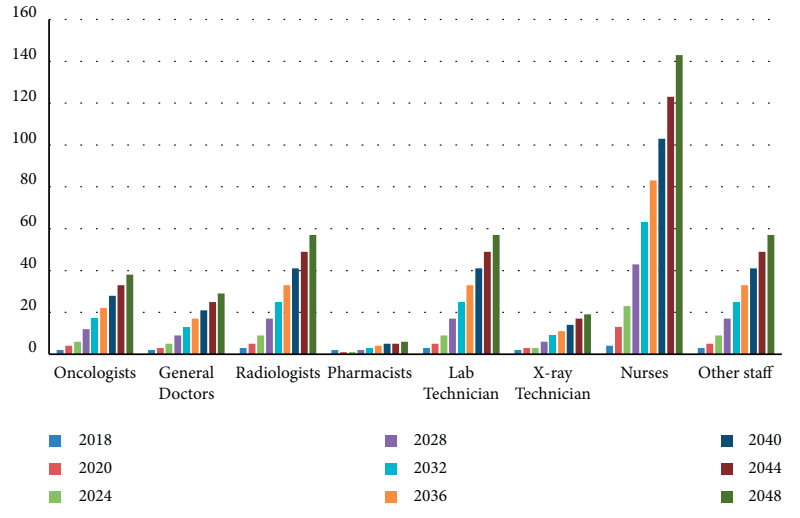

Figure 3: The staff growth using the GP model.

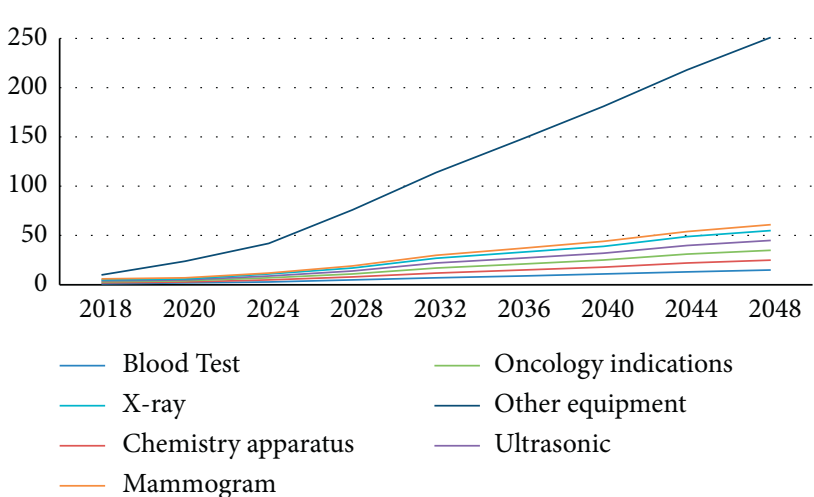

Figure 4: Medical devices growth using GP model. 
TABLE 11: Values of the neutrosophic variables.

\begin{tabular}{|c|c|c|c|c|c|}
\hline$\overline{\tilde{\tau}_{a}^{N}}$ & $a$ & $\left(a, l_{\mu}, r_{\mu} ; w_{a}\right),\left(a, l_{\sigma}, r_{\sigma} ; u_{a}\right),\left(a, l_{v}, r_{v} ; y_{a}\right)$ & $\alpha$ & $\beta$ & $\gamma$ \\
\hline$\widetilde{T B}^{N}$ & 570860 & $(100000,200000 ; 0.9),(30000,40000 ; 0.3),(800000,100000 ; 0.5)$ & 0.1 & 0.9 & 0.8 \\
\hline$(\widehat{T B S})^{N}$ & 135600 & $(13000,100000 ; 0.9),(18000,15000 ; 0.3),(20000,30000 ; 0.5)$ & 0.1 & 0.9 & 0.8 \\
\hline$(\widetilde{T B M})^{N}$ & 45260 & $(1000,5000 ; 0.9),(9000,10000 ; 0.3),(10000,15000 ; 0.5)$ & 0.1 & 0.9 & 0.8 \\
\hline$(\widetilde{T B D})^{N}$ & 390000 & $(10000,100000 ; 0.9),(20000,30000 ; 0.3),(15000,20000 ; 0.5)$ & 0.1 & 0.9 & 0.8 \\
\hline
\end{tabular}

TABLE 12: Budgets results of NGP model.

\begin{tabular}{|c|c|c|c|c|c|c|c|c|c|c|c|}
\hline Year & & 2018 & 2020 & 2024 & 2028 & 2032 & 2036 & 2040 & 2044 & 2048 & GR (\%) \\
\hline $\mathrm{TB}$ & Cost & 359415.6 & 407990.3 & 672852.8 & 920536.3 & 1196277 & 1579471 & 1921383 & 2288403 & 2613624 & 15 \\
\hline \multirow{2}{*}{ TBS } & Cost & 120960 & 151920 & 326160 & 494640 & 684000 & 940800 & 1178640 & 1425840 & 1651680 & 8 \\
\hline & $(\%)$ & 34 & 37 & 48 & 54 & 57 & 60 & 61 & 62 & 63 & \\
\hline \multirow{2}{*}{ TBM } & Cost & 26600 & 28000 & 62000 & 92200 & 122000 & 179200 & 214200 & 264000 & 298600 & 10 \\
\hline & $(\%)$ & 7 & 7 & 9 & 10 & 10 & 11 & 11 & 12 & 11 & \\
\hline \multirow{2}{*}{ TBD } & Cost & 211855.6 & 228070.3 & 284692.8 & 333696.3 & 390277.3 & 459470.6 & 528543.1 & 598563.4 & 663344 & 33 \\
\hline & $(\%)$ & 59 & 56 & 42 & 36 & 33 & 29 & 28 & 26 & 25 & \\
\hline
\end{tabular}

TABLE 13: The staff numbers obtained using the NGP model.

\begin{tabular}{|c|c|c|c|c|c|c|c|c|c|c|}
\hline & Staff & $\begin{array}{c}x_{1} \\
\text { Oncologists }\end{array}$ & $\begin{array}{c}x_{2} \\
\text { General } \\
\text { doctors }\end{array}$ & $\begin{array}{c}x_{3} \\
\text { Radiologists }\end{array}$ & $\begin{array}{c}x_{4} \\
\text { Pharmacists }\end{array}$ & $\begin{array}{c}x_{5} \\
\text { Lab } \\
\text { technician }\end{array}$ & $\begin{array}{c}x_{6} \\
\text { X-ray } \\
\text { technician }\end{array}$ & $\begin{array}{c}x_{7} \\
\text { Nurses }\end{array}$ & $\begin{array}{c}x_{8} \\
\text { Other } \\
\text { staff }\end{array}$ & Total \\
\hline \multirow{3}{*}{2018} & No. & 3 & 3 & 4 & 2 & 4 & 2 & 7 & 4 & 29 \\
\hline & $\begin{array}{c}\text { Ratio } \\
(\%)\end{array}$ & 10 & 10 & 14 & 7 & 14 & 7 & 24 & 14 & 100 \\
\hline & Cost & 28800 & 11520 & 23040 & 6720 & 13440 & 6240 & 16800 & 14400 & 120960 \\
\hline \multirow{3}{*}{2020} & No. & 4 & 2 & 6 & 1 & 6 & 3 & 10 & 4 & 36 \\
\hline & $\begin{array}{c}\text { Ratio } \\
(\%)\end{array}$ & 11 & 6 & 17 & 3 & 17 & 8 & 28 & 11 & 100 \\
\hline & Cost & 38400 & 7680 & 34560 & 3360 & 20160 & 9360 & 24000 & 14400 & 151920 \\
\hline \multirow{3}{*}{2024} & No. & 8 & 6 & 11 & 2 & 11 & 4 & 28 & 11 & 81 \\
\hline & $\begin{array}{c}\text { Ratio } \\
(\%)\end{array}$ & 10 & 7 & 14 & 2 & 14 & 5 & 35 & 14 & 100 \\
\hline & Cost & 76800 & 23040 & 63360 & 6720 & 36960 & 12480 & 67200 & 39600 & 326160 \\
\hline \multirow{3}{*}{2028} & No. & 12 & 9 & 17 & 2 & 17 & 6 & 43 & 17 & 123 \\
\hline & $\begin{array}{c}\text { Ratio } \\
(\%)\end{array}$ & 10 & 7 & 14 & 2 & 14 & 5 & 35 & 14 & 100 \\
\hline & Cost & 115200 & 34560 & 97920 & 6720 & 57120 & 18720 & 103200 & 61200 & 494640 \\
\hline \multirow{3}{*}{2032} & No. & 16 & 12 & 24 & 3 & 24 & 8 & 60 & 24 & 171 \\
\hline & $\begin{array}{c}\text { Ratio } \\
(\%)\end{array}$ & 9 & 7 & 14 & 2 & 14 & 5 & 35 & 14 & 100 \\
\hline & Cost & 153600 & 46080 & 138240 & 10080 & 80640 & 24960 & 144000 & 86400 & 684000 \\
\hline \multirow{3}{*}{2036} & No. & 22 & 17 & 33 & 4 & 33 & 11 & 82 & 33 & 235 \\
\hline & $\begin{array}{c}\text { Ratio } \\
(\%)\end{array}$ & 9 & 7 & 14 & 2 & 14 & 5 & 35 & 14 & 100 \\
\hline & Cost & 211200 & 65280 & 190080 & 13440 & 110880 & 34320 & 196800 & 118800 & 940800 \\
\hline \multirow{3}{*}{2040} & No. & 28 & 21 & 41 & 5 & 41 & 14 & 103 & 41 & 294 \\
\hline & $\begin{array}{c}\text { Ratio } \\
(\%)\end{array}$ & 10 & 7 & 14 & 2 & 14 & 5 & 35 & 14 & 100 \\
\hline & Cost & 268800 & 80640 & 236160 & 16800 & 137760 & 43680 & 247200 & 147600 & 1178640 \\
\hline \multirow{3}{*}{2044} & No. & 34 & 25 & 50 & 5 & 50 & 17 & 124 & 50 & 355 \\
\hline & $\begin{array}{c}\text { Ratio } \\
(\%)\end{array}$ & 10 & 7 & 14 & 1 & 14 & 5 & 35 & 14 & 100 \\
\hline & Cost & 326400 & 96000 & 288000 & 16800 & 168000 & 53040 & 297600 & 180000 & 1425840 \\
\hline \multirow{3}{*}{2048} & No. & 39 & 29 & 58 & 6 & 58 & 20 & 144 & 58 & 412 \\
\hline & $\begin{array}{c}\text { Ratio } \\
(\%)\end{array}$ & 9 & 7 & 14 & 1 & 14 & 5 & 35 & 14 & 100 \\
\hline & Cost & 374400 & 111360 & 334080 & 20160 & 194880 & 62400 & 345600 & 208800 & 1651680 \\
\hline $\begin{array}{l}\text { GR } \\
(\%)\end{array}$ & 8 & 11 & 8 & 35 & 8 & 11 & 5 & 8 & 8 & \\
\hline
\end{tabular}


TABLE 14: The medical devices numbered obtained using NGP model.

\begin{tabular}{|c|c|c|c|c|c|c|c|c|c|}
\hline \multicolumn{2}{|c|}{ Medical devices } & \multirow{2}{*}{$\begin{array}{c}\begin{array}{c}y_{1} \\
\text { Blood Test }\end{array} \\
1\end{array}$} & \multirow{2}{*}{$\begin{array}{c}y_{2} \\
\text { Chemistry apparatus } \\
1\end{array}$} & \multirow{2}{*}{$\begin{array}{c}y_{3} \\
\text { Oncology indications } \\
1\end{array}$} & \multirow{2}{*}{$\begin{array}{c}y_{4} \\
\text { Ultrasonic }\end{array}$} & \multirow{2}{*}{$\begin{array}{c}\begin{array}{c}y_{5} \\
\text { X-ray }\end{array} \\
1\end{array}$} & \multirow{2}{*}{$\begin{array}{c}y_{6} \\
\text { Mammogram } \\
1\end{array}$} & \multirow{2}{*}{$\begin{array}{c}y_{7} \\
\text { Other devices } \\
7\end{array}$} & \multirow{2}{*}{$\begin{array}{c}\text { Total } \\
13\end{array}$} \\
\hline & No. & & & & & & & & \\
\hline \multirow[t]{3}{*}{2018} & Ratio (\%) & 8 & 8 & 8 & 8 & 8 & 8 & 54 & 100 \\
\hline & Cost & 4200 & 4800 & 6660 & 3200 & 3200 & 3200 & 1400 & 26660 \\
\hline & No. & 1 & 1 & 1 & 1 & 1 & 1 & 14 & 20 \\
\hline \multirow[t]{3}{*}{2020} & Ratio (\%) & 5 & 5 & 5 & 5 & 5 & 5 & 70 & 100 \\
\hline & Cost & 4200 & 4800 & 6660 & 3200 & 3200 & 3200 & 2800 & 28060 \\
\hline & No. & 3 & 2 & 2 & 2 & 2 & 2 & 37 & 50 \\
\hline \multirow[t]{3}{*}{2024} & Ratio (\%) & 6 & 4 & 4 & 4 & 4 & 4 & 74 & 100 \\
\hline & Cost & 12600 & 9600 & 13320 & 6400 & 6400 & 6400 & 7400 & 62120 \\
\hline & No. & 5 & 3 & 3 & 3 & 3 & 2 & 57 & 76 \\
\hline \multirow[t]{3}{*}{2028} & Ratio (\%) & 7 & 4 & 4 & 4 & 4 & 3 & 75 & 100 \\
\hline & Cost & 21000 & 14400 & 19980 & 9600 & 9600 & 6400 & 11400 & 92380 \\
\hline & No. & 6 & 4 & 4 & 4 & 4 & 3 & 80 & 105 \\
\hline \multirow[t]{3}{*}{2032} & Ratio (\%) & 6 & 4 & 4 & 4 & 4 & 3 & 76 & 100 \\
\hline & Cost & 25200 & 19200 & 26640 & 12800 & 12800 & 9600 & 16000 & 122240 \\
\hline & No. & 9 & 6 & 6 & 6 & 6 & 4 & 109 & 146 \\
\hline \multirow[t]{3}{*}{2036} & Ratio (\%) & 6 & 4 & 4 & 4 & 4 & 3 & 75 & 100 \\
\hline & Cost & 37800 & 28800 & 39960 & 19200 & 19200 & 12800 & 21800 & 179560 \\
\hline & No. & 11 & 7 & 7 & 7 & 7 & 5 & 137 & 181 \\
\hline \multirow[t]{3}{*}{2040} & Ratio (\%) & 6 & 4 & 4 & 4 & 4 & 3 & 76 & 100 \\
\hline & Cost & 46200 & 33600 & 46620 & 22400 & 22400 & 16000 & 27400 & 214620 \\
\hline & No. & 13 & 9 & 9 & 9 & 9 & 5 & 166 & 220 \\
\hline \multirow[t]{3}{*}{2044} & Ratio (\%) & 6 & 4 & 4 & 4 & 4 & 2 & 75 & 100 \\
\hline & Cost & 54600 & 43200 & 59940 & 28800 & 28800 & 16000 & 33200 & 264540 \\
\hline & No. & 15 & 10 & 10 & 10 & 10 & 6 & 192 & 253 \\
\hline \multirow[t]{2}{*}{2048} & Ratio (\%) & 6 & 4 & 4 & 4 & 4 & 2 & 76 & 100 \\
\hline & Cost & 63000 & 48000 & 66600 & 32000 & 32000 & 19200 & 38400 & 299200 \\
\hline GR & 7 & 11 & 11 & 11 & 11 & 18 & 4 & 6 & \\
\hline
\end{tabular}

TABle 15: The medical drugs quantities obtained using NGP model.

\begin{tabular}{|c|c|c|c|c|c|c|c|c|c|c|}
\hline Medical drug names & 2018 & 2020 & 2024 & 2028 & 2032 & 2036 & 2040 & 2044 & 2048 & GR (\%) \\
\hline$z_{1}$ & 14044 & 15124 & 18905 & 22145 & 25926 & 30517 & 35108 & 39753 & 44074 & 33 \\
\hline$z_{2}$ & 84 & 90 & 112 & 132 & 154 & 181 & 208 & 236 & 262 & 33 \\
\hline$z_{3}$ & 504 & 543 & 678 & 794 & 930 & 1094 & 1259 & 1425 & 1580 & 33 \\
\hline$z_{4}$ & 1104 & 1189 & 1486 & 1741 & 2038 & 2398 & 2759 & 3124 & 3464 & 33 \\
\hline$z_{5}$ & 1091 & 1175 & 1469 & 1721 & 2015 & 2371 & 2728 & 3089 & 3424 & 33 \\
\hline$z_{6}$ & 381 & 410 & 513 & 601 & 703 & 828 & 952 & 1078 & 1195 & 33 \\
\hline$z_{7}$ & 635 & 684 & 854 & 1001 & 1172 & 1379 & 1586 & 1796 & 1992 & 33 \\
\hline$z_{8}$ & 722 & 778 & 972 & 1139 & 1333 & 1569 & 1805 & 2044 & 2266 & 33 \\
\hline$z_{9}$ & 162 & 174 & 217 & 255 & 298 & 351 & 403 & 457 & 506 & 33 \\
\hline$z_{10}$ & 630 & 678 & 847 & 993 & 1162 & 1368 & 1573 & 1782 & 1975 & 33 \\
\hline$z_{11}$ & 4717 & 5080 & 6349 & 7438 & 8708 & 10250 & 11791 & 13352 & 14803 & 33 \\
\hline$z_{12}$ & 219 & 236 & 294 & 345 & 404 & 475 & 546 & 619 & 686 & 33 \\
\hline$z_{13}$ & 286 & 308 & 385 & 451 & 528 & 622 & 715 & 810 & 898 & 33 \\
\hline$z_{14}$ & 162 & 174 & 217 & 255 & 298 & 351 & 403 & 457 & 506 & 33 \\
\hline$z_{15}$ & 115 & 124 & 154 & 181 & 212 & 249 & 286 & 324 & 360 & 33 \\
\hline$z_{16}$ & 236 & 254 & 317 & 371 & 434 & 511 & 588 & 666 & 738 & 33 \\
\hline$z_{17}$ & 6629 & 7139 & 8924 & 10454 & 12239 & 14406 & 16573 & 18766 & 20805 & 33 \\
\hline$z_{18}$ & 810 & 872 & 1090 & 1276 & 1494 & 1759 & 2023 & 2291 & 2540 & 33 \\
\hline$z_{19}$ & 822 & 885 & 1106 & 1296 & 1517 & 1786 & 2054 & 2326 & 2579 & 33 \\
\hline$z_{20}$ & 787 & 847 & 1059 & 1240 & 1452 & 1709 & 1966 & 2226 & 2468 & 33 \\
\hline$z_{21}$ & 159 & 171 & 213 & 250 & 292 & 344 & 396 & 448 & 497 & 33 \\
\hline$z_{22}$ & 222 & 239 & 299 & 350 & 409 & 482 & 554 & 628 & 696 & 33 \\
\hline$z_{23}$ & 2678 & 2884 & 3605 & 4223 & 4944 & 5820 & 6695 & 7581 & 8405 & 33 \\
\hline$z_{24}$ & 2083 & 2243 & 2803 & 3284 & 3844 & 4525 & 5206 & 5894 & 6535 & 33 \\
\hline$z_{25}$ & 293 & 315 & 394 & 461 & 540 & 636 & 731 & 828 & 918 & 33 \\
\hline$z_{26}$ & 273 & 294 & 367 & 430 & 504 & 593 & 682 & 772 & 856 & 33 \\
\hline
\end{tabular}


Table 15: Continued.

\begin{tabular}{lcccccccccc}
\hline Medical drug names & 2018 & 2020 & 2024 & 2028 & 2032 & 2036 & 2040 & 2044 & 2048 & GR (\%) \\
\hline$z_{27}$ & 428 & 461 & 576 & 675 & 790 & 929 & 1069 & 1210 & 1342 & 33 \\
$z_{28}$ & 165 & 177 & 222 & 260 & 304 & 358 & 411 & 466 & 516 & 33 \\
$z_{29}$ & 950 & 1023 & 1279 & 1498 & 1753 & 2064 & 2374 & 2688 & 2981 \\
$z_{30}$ & 115 & 124 & 154 & 181 & 212 & 249 & 286 & 324 & 360 & 33 \\
$z_{31}$ & 128 & 138 & 173 & 202 & 237 & 278 & 320 & 363 & 402 & 33 \\
$z_{32}$ & 818 & 881 & 1101 & 1290 & 1510 & 1777 & 2044 & 2314 & 2566 \\
$z_{33}$ & 346 & 372 & 465 & 545 & 638 & 751 & 864 & 978 & 1084 \\
$z_{34}$ & 177 & 191 & 238 & 279 & 327 & 385 & 442 & 501 & 555 \\
$z_{35}$ & 250 & 269 & 336 & 394 & 461 & 543 & 624 & 707 & 784 \\
$z_{36}$ & 298 & 321 & 401 & 470 & 550 & 647 & 744 & 842 & 934 \\
$z_{37}$ & 2193 & 2361 & 2952 & 3458 & 4048 & 4765 & 5481 & 6206 & 6881 \\
$z_{38}$ & 43 & 46 & 58 & 68 & 79 & 93 & 107 & 121 & 134 \\
$z_{39}$ & 55 & 59 & 73 & 86 & 100 & 118 & 136 & 154 & 134 \\
$z_{40}$ & 175 & 189 & 236 & 276 & 323 & 380 & 437 & 495 & 54 \\
Sum & 45989 & 49522 & 61893 & 72509 & 84882 & 99911 & 114929 & 130141 & 144286 \\
\hline
\end{tabular}

TABLE 16: The negative deviational variables obtained using the NGP model.

\begin{tabular}{lccccccccc}
\hline Negative deviations & 2018 & 2020 & 2024 & 2028 & 2032 & 2036 & 2040 & 2044 & 2048 \\
\hline N1 & 0 & 0 & 0 & 0 & 0 & 0 & 0 & 0 \\
N2 & 0 & 0 & 0 & 0 & 0 & 0 & 0 & 0 \\
N3 & 20064 & 0 & 0 & 0 & 0 & 0 & 0 & 0 \\
N4 & 0 & 0 & 0 & 0 & 0 & 0 & 0 & 0 \\
\hline
\end{tabular}

TABLe 17: The positive deviational variables obtained using the NGP model.

\begin{tabular}{lccccccccc}
\hline Positive deviations & 2018 & 2020 & 2024 & 2028 & 2032 & 2036 & 2040 & 2044 & 2048 \\
\hline P1 & 0 & 96 & 276448.6 & 691594.3 & 8885665.6 & 1352026 & 1960156 & 2190713 & 2575798 \\
P2 & 20064 & 48 & 136320 & 249634.3 & 423648 & 634344 & 790216.4 & 1026634 & 1209082 \\
P3 & 0 & 0 & 3808.571 & 15674.12 & 41269.57 & 83338.05 & 99665.71 & 137445.5 & 157635 \\
P4 & 0 & 48 & 136320 & 249634.3 & 423648 & 634344 & 790216.4 & 1026634 & 1209082 \\
PX1 & 1.666667 & 1.333333 & 0.666667 & 0.666667 & 0 & 0.333333 & 0.666667 & 0.933333 & 0.6 \\
PX2 & 2 & 0 & 0.5 & 0.5 & 0 & 0.75 & 0.5 & 0.2 & 0.2 \\
PX3 & 2 & 2 & 0 & 0 & 0 & 0.5 & 0 & 0.4 \\
PX4 & 1.8 & 0.6 & 0.9 & 0.3 & 0.6 & 0.75 & 0.9 & $4.00 \mathrm{E}-02$ & 0.4 \\
PX5 & 2 & 2 & 0 & 0 & 0 & 0.5 & 0 & 0.4 \\
PX6 & 1.333333 & 1.666667 & 0.333333 & 0.333333 & 0 & 0.166667 & 0.333333 & 0.466667 & 0.4 \\
PX7 & 2 & 0 & 0.5 & 0.5 & 0 & 0.75 & 0.5 & 0 \\
PX8 & 2 & 0 & 0 & 0 & 0 & 0.5 & 0 & 0.4 \\
PY1 & 0.5 & 0 & 0.25 & 0.75 & 0 & 0.875 & 0.75 & 0.6 & 0.4 \\
PY2 & 0.666667 & 0.333333 & 0.166667 & 0.166667 & 0 & 0.583333 & 0.166667 & 0.733333 \\
PY3 & 0.666667 & 0.333333 & 0.166667 & 0.166667 & 0 & 0.583333 & 0.166667 & 0.733333 & 0.6 \\
PY4 & 0.666667 & 0.333333 & 0.166667 & 0.166667 & 0 & 0.583333 & 0.166667 & 0.733333 & 0.4 \\
PY5 & 0.666667 & 0.333333 & 0.166667 & 0.166667 & 0 & 0.583333 & 0.166667 & 0.733333 & 0.4 \\
PY6 & 0.8 & 0.6 & 0.9 & 0.3 & 0.6 & 0.75 & 0.9 & $4.00 \mathrm{E}-02$ & 0.24 \\
PY7 & 0.333333 & 0.666667 & 0.333333 & 0.333333 & 0 & 0.666667 & 0.333333 & 0.666667 & 0 \\
\hline
\end{tabular}

TABLE 18: Values of the neutrosophic variables.

\begin{tabular}{lcc}
\hline$\tilde{\tau}_{g}^{N}$ & $g$ & $\left\langle g_{1}, g_{2}, g_{3}\right\rangle$ \\
\hline$\widetilde{\mathrm{TB}}^{N}$ & 570860 & $\langle 615304.4,575145.7143,590860\rangle$ \\
$\left(\widetilde{\mathrm{TBS}}^{N}\right.$ & 135600 & $\langle 174266.7,134314.3,131600\rangle$ \\
$(\widetilde{\mathrm{TBM}})^{N}$ & 45260 & $\langle 47037.78,45688.57,47260\rangle$ \\
$(\overline{\mathrm{TBD}})^{N}$ & 390000 & $\langle 430000,394285.7,392000\rangle$ \\
\hline
\end{tabular}


TABle 19: The obtained budgets using NMCGP model.

\begin{tabular}{lcccccccccccc}
\hline \multicolumn{2}{c}{ Year } & 2018 & 2020 & 2024 & 2028 & 2032 & 2036 & 2040 & 2044 & 2048 & GR (\%) \\
\hline TB & Cost & 337882.6 & 512647.8 & 585093.9 & 874117.3 & 1299211 & 1586187 & 1940197 & 2164600 & 2618038 & 14 \\
& Cost & 90720 & 208320 & 259200 & 461280 & 747600 & 943200 & 1193760 & 1347120 & 1654080 & 6 \\
TBS & $(\%)$ & 15 & 36 & 32 & 50 & 57 & 59 & 61 & 62 & 63 \\
& Cost & 27200 & 52000 & 57400 & 87400 & 145400 & 179400 & 214400 & 240200 & 298800 & 10 \\
TBM & $(\%)$ & 10 & 8 & 7 & 9 & 11 & 11 & 11 & 12 & 12 & 52 \\
& Cost & 219962.6 & 252327.8 & 268493.9 & 325437.3 & 406211.4 & 463587.2 & 532037.4 & 577280.5 & 665157.6 & 34 \\
TBD & $(\%)$ & 76 & 56 & 61 & 41 & 32 & 29 & 28 & 26 & 26 \\
& & & & & & & & & & 26 &
\end{tabular}

TABLE 20: The staff number obtained using the NMCGP model.

\begin{tabular}{|c|c|c|c|c|c|c|c|c|c|c|}
\hline \multicolumn{2}{|r|}{ Staff } & $\begin{array}{c}x_{1} \\
\text { Oncologists }\end{array}$ & $\begin{array}{c}x_{2} \\
\text { General } \\
\text { doctors }\end{array}$ & $\begin{array}{c}x_{3} \\
\text { Radiologists }\end{array}$ & $\begin{array}{c}x_{4} \\
\text { Pharmacists }\end{array}$ & $\begin{array}{c}x_{5} \\
\text { Lab } \\
\text { technician }\end{array}$ & $\begin{array}{c}x_{6} \\
\text { X-ray } \\
\text { technician }\end{array}$ & $\begin{array}{c}x_{7} \\
\text { Nurses }\end{array}$ & $\begin{array}{c}x_{8} \\
\text { Other } \\
\text { staff }\end{array}$ & Total \\
\hline \multirow{3}{*}{2018} & No. & 2 & 2 & 3 & 1 & 3 & 1 & 8 & 3 & 23 \\
\hline & $\begin{array}{c}\text { Ratio } \\
(\%)\end{array}$ & 9 & 9 & 13 & 4 & 13 & 4 & 35 & 13 & 100 \\
\hline & Cost & 19200 & 7680 & 17280 & 3360 & 10080 & 3120 & 19200 & 10800 & 90720 \\
\hline \multirow{3}{*}{2020} & No. & 5 & 4 & 7 & 1 & 7 & 3 & 18 & 7 & 52 \\
\hline & $\begin{array}{c}\text { Ratio } \\
(\%)\end{array}$ & 10 & 8 & 13 & 2 & 13 & 6 & 35 & 13 & 100 \\
\hline & Cost & 48000 & 15360 & 40320 & 3360 & 23520 & 9360 & 43200 & 25200 & 208320 \\
\hline \multirow{3}{*}{2024} & No. & 6 & 5 & 9 & 1 & 9 & 3 & 23 & 9 & 65 \\
\hline & $\begin{array}{c}\text { Ratio } \\
(\%)\end{array}$ & 9 & 8 & 14 & 2 & 14 & 5 & 35 & 14 & 100 \\
\hline & Cost & 57600 & 19200 & 51840 & 3360 & 30240 & 9360 & 55200 & 32400 & 259200 \\
\hline \multirow{3}{*}{2028} & No. & 11 & 8 & 16 & 2 & 16 & 6 & 40 & 16 & 115 \\
\hline & $\begin{array}{c}\text { Ratio } \\
(\%)\end{array}$ & 10 & 7 & 14 & 2 & 14 & 5 & 35 & 14 & 100 \\
\hline & Cost & 105600 & 30720 & 92160 & 6720 & 53760 & 18720 & 96000 & 57600 & 461280 \\
\hline \multirow{3}{*}{2032} & No. & 18 & 13 & 26 & 3 & 26 & 9 & 65 & 26 & 186 \\
\hline & $\begin{array}{c}\text { Ratio } \\
(\%)\end{array}$ & 10 & 7 & 14 & 2 & 14 & 5 & 35 & 14 & 100 \\
\hline & Cost & 172800 & 49920 & 149760 & 10080 & 87360 & 28080 & 156000 & 93600 & 747600 \\
\hline \multirow{3}{*}{2036} & No. & 22 & 17 & 33 & 4 & 33 & 11 & 83 & 33 & 236 \\
\hline & $\begin{array}{c}\text { Ratio } \\
(\%)\end{array}$ & 9 & 7 & 14 & 2 & 14 & 5 & 35 & 14 & 100 \\
\hline & Cost & 211200 & 65280 & 190080 & 13440 & 110880 & 34320 & 199200 & 118800 & 943200 \\
\hline \multirow{3}{*}{2040} & No. & 28 & 21 & 42 & 5 & 42 & 14 & 104 & 42 & 298 \\
\hline & $\begin{array}{c}\text { Ratio } \\
(\%)\end{array}$ & 9 & 7 & 14 & 2 & 14 & 5 & 35 & 14 & 100 \\
\hline & Cost & 268800 & 80640 & 241920 & 16800 & 141120 & 43680 & 249600 & 151200 & 1193760 \\
\hline \multirow{3}{*}{2044} & No. & 32 & 24 & 47 & 5 & 47 & 16 & 118 & 47 & 336 \\
\hline & $\begin{array}{c}\text { Ratio } \\
(\%)\end{array}$ & 10 & 7 & 14 & 1 & 14 & 5 & 35 & 14 & 100 \\
\hline & Cost & 307200 & 92160 & 270720 & 16800 & 157920 & 49920 & 283200 & 169200 & 1347120 \\
\hline \multirow{3}{*}{2048} & No. & 39 & 29 & 58 & 6 & 58 & 20 & 145 & 58 & 413 \\
\hline & $\begin{array}{c}\text { Ratio } \\
(\%)\end{array}$ & 9 & 7 & 14 & 1 & 14 & 5 & 35 & 14 & 100 \\
\hline & Cost & 374400 & 111360 & 334080 & 20160 & 194880 & 62400 & 348000 & 208800 & 1654080 \\
\hline $\begin{array}{l}\text { GR } \\
(\%)\end{array}$ & 6 & 8 & 6 & 18 & 6 & 6 & 6 & 6 & 6 & \\
\hline
\end{tabular}


TABLE 21: The medical devices numbered obtained using NMCGP model.

\begin{tabular}{|c|c|c|c|c|c|c|c|c|c|}
\hline \multicolumn{2}{|c|}{ Medical devices } & \multirow{2}{*}{$\begin{array}{c}y_{1} \\
\text { Blood test }\end{array}$} & \multirow{2}{*}{$\begin{array}{c}y_{2} \\
\text { Chemistry apparatus } \\
1\end{array}$} & \multirow{2}{*}{$\begin{array}{c}y_{3} \\
\text { Oncology indications } \\
1\end{array}$} & \multirow{2}{*}{$\begin{array}{c}y_{4} \\
\text { Ultrasonic } \\
1\end{array}$} & \multirow{2}{*}{$\begin{array}{c}y_{5} \\
\text { X-ray } \\
1\end{array}$} & \multirow{2}{*}{$\begin{array}{c}y_{6} \\
\text { Mammogram } \\
1\end{array}$} & \multirow{2}{*}{$\begin{array}{c}y_{7} \\
\text { Other devices } \\
10\end{array}$} & \multirow{2}{*}{$\begin{array}{c}\text { Total } \\
16\end{array}$} \\
\hline & No. & & & & & & & & \\
\hline \multirow{3}{*}{2018} & Ratio (\%) & 6 & 6 & 6 & 6 & 6 & 6 & 63 & 100 \\
\hline & Cost & 4200 & 4800 & 6660 & 3200 & 3200 & 3200 & 2000 & 27260 \\
\hline & No. & 2 & 2 & 2 & 2 & 2 & 1 & 24 & 35 \\
\hline \multirow[t]{3}{*}{2020} & Ratio (\%) & 6 & 6 & 6 & 6 & 6 & 3 & 69 & 100 \\
\hline & Cost & 8400 & 9600 & 13320 & 6400 & 6400 & 3200 & 4800 & 52120 \\
\hline & No. & 3 & 2 & 2 & 2 & 2 & 1 & 30 & 42 \\
\hline \multirow[t]{3}{*}{2024} & Ratio (\%) & 7 & 5 & 5 & 5 & 5 & 2 & 71 & 100 \\
\hline & Cost & 12600 & 9600 & 13320 & 6400 & 6400 & 3200 & 6000 & 57520 \\
\hline & No. & 4 & 3 & 3 & 3 & 3 & 2 & 54 & 72 \\
\hline \multirow[t]{3}{*}{2028} & Ratio (\%) & 6 & 4 & 4 & 4 & 4 & 3 & 75 & 100 \\
\hline & Cost & 16800 & 14400 & 19980 & 9600 & 9600 & 6400 & 10800 & 87580 \\
\hline & No. & 7 & 5 & 5 & 5 & 5 & 3 & 87 & 117 \\
\hline \multirow[t]{3}{*}{2032} & Ratio (\%) & $6 \%$ & $4 \%$ & $4 \%$ & $4 \%$ & $4 \%$ & $3 \%$ & $74 \%$ & $100 \%$ \\
\hline & Cost & 29400 & 24000 & 33300 & 16000 & 16000 & 9600 & 17400 & 145700 \\
\hline & No. & 9 & 6 & 6 & 6 & 6 & 4 & 110 & 147 \\
\hline \multirow[t]{3}{*}{2036} & Ratio (\%) & 6 & 4 & 4 & 4 & 4 & 3 & 75 & 100 \\
\hline & Cost & 37800 & 28800 & 39960 & 19200 & 19200 & 12800 & 22000 & 179760 \\
\hline & No. & 11 & 7 & 7 & 7 & 7 & 5 & 138 & 182 \\
\hline \multirow[t]{3}{*}{2040} & Ratio (\%) & 6 & 4 & 4 & 4 & 4 & 3 & 76 & 100 \\
\hline & Cost & 46200 & 33600 & 46620 & 22400 & 22400 & 16000 & 27600 & 214820 \\
\hline & No. & 12 & 8 & 8 & 8 & 8 & 5 & 157 & 206 \\
\hline \multirow[t]{3}{*}{2044} & Ratio (\%) & 6 & 4 & 4 & 4 & 4 & 2 & 76 & 100 \\
\hline & Cost & 50400 & 38400 & 53280 & 25600 & 25600 & 16000 & 31400 & 240680 \\
\hline & No. & 15 & 10 & 10 & 10 & 10 & 6 & 193 & 254 \\
\hline \multirow[t]{2}{*}{2048} & Ratio (\%) & $6 \%$ & $4 \%$ & $4 \%$ & $4 \%$ & $4 \%$ & $2 \%$ & $76 \%$ & $100 \%$ \\
\hline & Cost & 63000 & 48000 & 66600 & 32000 & 32000 & 19200 & 38600 & 299400 \\
\hline GR (\%) & 7 & 11 & 11 & 11 & 11 & 18 & 6 & 7 & \\
\hline
\end{tabular}

TABLE 22: Medical drugs quantities obtained using the NMCGP model.

\begin{tabular}{|c|c|c|c|c|c|c|c|c|c|c|}
\hline Medicament name & 2018 & 2020 & 2024 & 2028 & 2032 & 2036 & 2040 & 2044 & 2048 & GR (\%) \\
\hline$z_{1}$ & 14584 & 16744 & 17824 & 21605 & 27006 & 30787 & 35324 & 38349 & 44182 & 34 \\
\hline$z_{2}$ & 87 & 100 & 106 & 128 & 160 & 183 & 210 & 228 & 262 & 34 \\
\hline$z_{3}$ & 523 & 601 & 639 & 775 & 968 & 1104 & 1267 & 1375 & 1584 & 34 \\
\hline$z_{4}$ & 1146 & 1316 & 1401 & 1698 & 2122 & 2420 & 2776 & 3014 & 3472 & 34 \\
\hline$z_{5}$ & 1133 & 1301 & 1385 & 1679 & 2098 & 2392 & 2745 & 2980 & 3433 & 34 \\
\hline$z_{6}$ & 396 & 454 & 484 & 586 & 732 & 835 & 958 & 1040 & 1198 & 34 \\
\hline$z_{7}$ & 659 & 757 & 806 & 976 & 1220 & 1391 & 1596 & 1733 & 1996 & 34 \\
\hline$z_{8}$ & 750 & 861 & 917 & 1111 & 1388 & 1583 & 1816 & 1971 & 2271 & 34 \\
\hline$z_{9}$ & 168 & 193 & 205 & 248 & 310 & 354 & 406 & 441 & 508 & 34 \\
\hline$z_{10}$ & 654 & 751 & 799 & 968 & 1210 & 1380 & 1583 & 1719 & 1980 & 34 \\
\hline$z_{11}$ & 4898 & 5624 & 5987 & 7256 & 9070 & 10340 & 11864 & 12880 & 14839 & 34 \\
\hline$z_{12}$ & 227 & 261 & 278 & 336 & 420 & 479 & 550 & 597 & 688 & 34 \\
\hline$z_{13}$ & 297 & 341 & 363 & 440 & 550 & 627 & 720 & 781 & 900 & 34 \\
\hline$z_{14}$ & 168 & 193 & 205 & 248 & 310 & 354 & 406 & 441 & 508 & 34 \\
\hline$z_{15}$ & 119 & 137 & 146 & 176 & 220 & 251 & 288 & 313 & 360 & 34 \\
\hline$z_{16}$ & 245 & 281 & 299 & 362 & 452 & 516 & 592 & 642 & 740 & 34 \\
\hline$z_{17}$ & 6884 & 7904 & 8414 & 10199 & 12748 & 14533 & 16675 & 18103 & 20856 & 34 \\
\hline$z_{18}$ & 841 & 965 & 1027 & 1245 & 1556 & 1774 & 2036 & 2210 & 2546 & 34 \\
\hline$z_{19}$ & 854 & 980 & 1043 & 1264 & 1580 & 1802 & 2067 & 2244 & 2585 & 34 \\
\hline$z_{20}$ & 817 & 938 & 998 & 1210 & 1512 & 1724 & 1978 & 2148 & 2474 & 34 \\
\hline$z_{21}$ & 165 & 189 & 201 & 244 & 304 & 347 & 398 & 432 & 498 & 34 \\
\hline$z_{22}$ & 231 & 265 & 282 & 341 & 426 & 486 & 558 & 605 & 697 & 34 \\
\hline$z_{23}$ & 2781 & 3193 & 3399 & 4120 & 5150 & 5871 & 6737 & 7313 & 8426 & 34 \\
\hline$z_{24}$ & 2163 & 2483 & 2643 & 3204 & 4004 & 4565 & 5238 & 5686 & 6551 & 34 \\
\hline$z_{25}$ & 304 & 349 & 371 & 450 & 562 & 641 & 736 & 799 & 920 & 34 \\
\hline$z_{26}$ & 283 & 325 & 346 & 420 & 524 & 598 & 686 & 745 & 858 & 34 \\
\hline
\end{tabular}


TABle 22: Continued.

\begin{tabular}{|c|c|c|c|c|c|c|c|c|c|c|}
\hline Medicament name & 2018 & 2020 & 2024 & 2028 & 2032 & 2036 & 2040 & 2044 & 2048 & GR (\%) \\
\hline$z_{27}$ & 444 & 510 & 543 & 658 & 822 & 938 & 1076 & 1168 & 1345 & 34 \\
\hline$z_{28}$ & 171 & 196 & 209 & 253 & 316 & 361 & 414 & 449 & 517 & 34 \\
\hline$z_{29}$ & 987 & 1133 & 1206 & 1461 & 1826 & 2082 & 2389 & 2593 & 2988 & 34 \\
\hline$z_{30}$ & 119 & 137 & 146 & 176 & 220 & 251 & 288 & 313 & 360 & 34 \\
\hline$z_{31}$ & 133 & 153 & 163 & 197 & 246 & 281 & 322 & 350 & 403 & 34 \\
\hline$z_{32}$ & 849 & 975 & 1038 & 1258 & 1572 & 1793 & 2057 & 2233 & 2572 & 34 \\
\hline$z_{33}$ & 359 & 412 & 439 & 532 & 664 & 757 & 869 & 943 & 1087 & 34 \\
\hline$z_{34}$ & 184 & 211 & 225 & 272 & 340 & 388 & 445 & 483 & 557 & 34 \\
\hline$z_{35}$ & 260 & 298 & 317 & 384 & 480 & 548 & 628 & 682 & 786 & 34 \\
\hline$z_{36}$ & 309 & 355 & 378 & 458 & 572 & 653 & 749 & 813 & 936 & 34 \\
\hline$z_{37}$ & 2277 & 2614 & 2783 & 3373 & 4216 & 4807 & 5515 & 5987 & 6898 & 34 \\
\hline$z_{38}$ & 45 & 51 & 55 & 66 & 82 & 94 & 108 & 117 & 135 & 35 \\
\hline$z_{39}$ & 57 & 65 & 69 & 84 & 104 & 119 & 137 & 148 & 171 & 35 \\
\hline$z_{40}$ & 182 & 209 & 222 & 269 & 336 & 384 & 440 & 478 & 550 & 34 \\
\hline Sum & 47753 & 54825 & 58361 & 70730 & 88398 & 100793 & 115647 & 125546 & 144637 & 34 \\
\hline
\end{tabular}

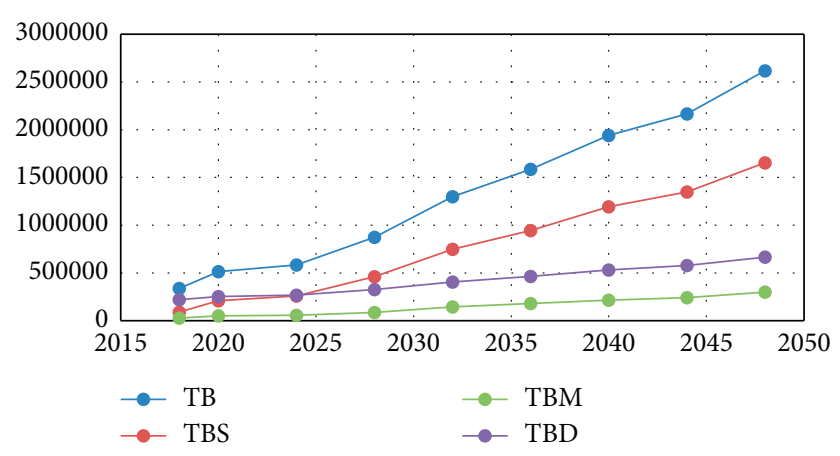

FIgURE 5: Budget growth using the NMCGP model.

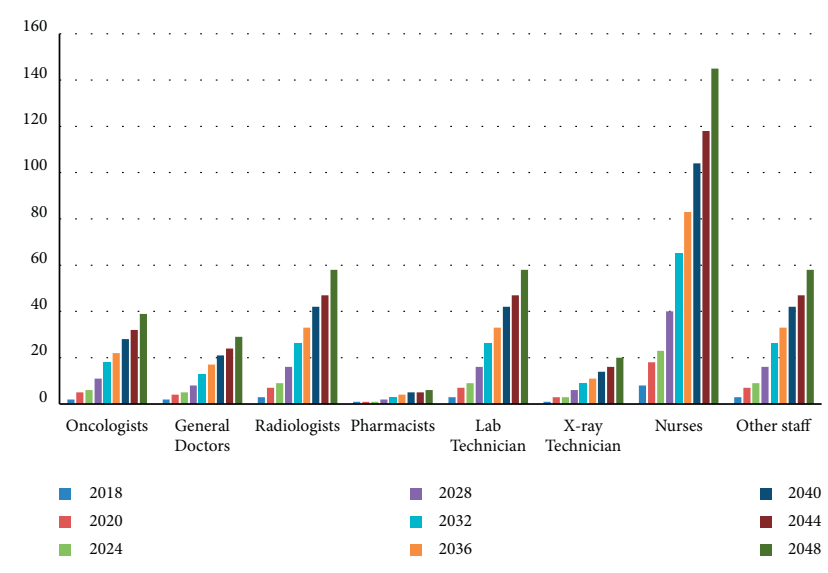

Figure 6: The staff growth using the NMCGP model.

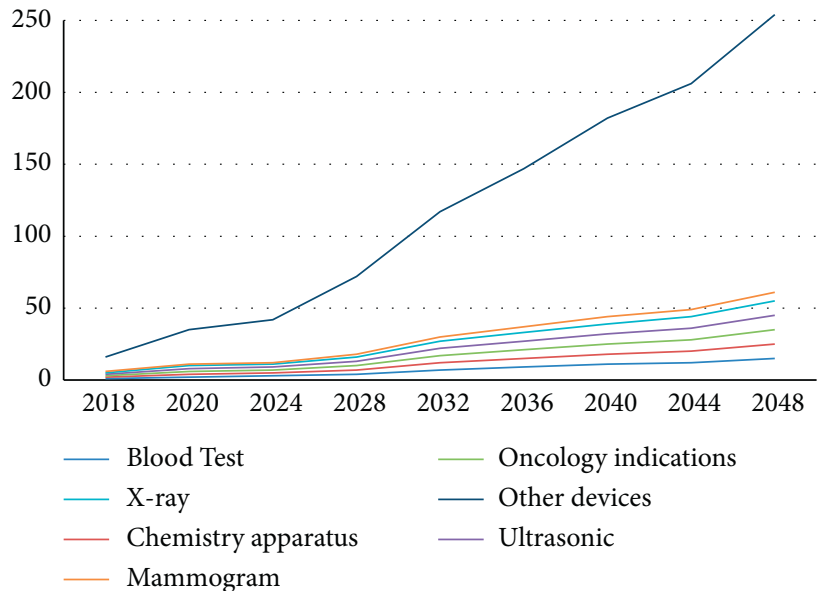

FIGURE 7: The medical devices growth using the NMCGP model. 
TABLE 23: Summary of the comparison between the proposed models.

\begin{tabular}{lccccccccccc}
\hline & & 2018 & 2020 & 2024 & 2028 & 2032 & 2036 & 2040 & 2044 & 2048 & GR (\%) \\
\hline \multirow{4}{*}{ Total Budget } & GP & 316705.7 & 426305.1 & 585093.9 & 920536.3 & 1263664 & 1586187 & 1921383 & 2258103 & 2580579 & 13 \\
& NGP & 359415.6 & 407990.3 & 672852.8 & 920536.3 & 1196277 & 1579471 & 1921383 & 2288403 & 2613624 & 15 \\
& MCNGP & 337882.6 & 512647.8 & 585093.9 & 874117.3 & 1299211 & 1586187 & 1940197 & 2164600 & 2618038 & 14 \\
Total Staff & GP & 21 & 39 & 65 & 123 & 180 & 236 & 294 & 350 & 406 & 6 \\
& NGP & 29 & 36 & 81 & 123 & 171 & 235 & 294 & 355 & 412 & 8 \\
Total Devices & MCNGP & 23 & 52 & 65 & 115 & 186 & 236 & 298 & 336 & 413 & 6 \\
& GP & 10 & 24 & 42 & 76 & 114 & 147 & 181 & 218 & 251 & 4 \\
& NGP & 13 & 20 & 50 & 76 & 105 & 146 & 181 & 220 & 253 & 6 \\
Total Medicines & MCNGP & 16 & 35 & 42 & 72 & 117 & 147 & 182 & 206 & 254 & 7 \\
& GP & 44199 & 51288 & 58361 & 72509 & 86646 & 100793 & 114929 & 129081 & 143223 & 32 \\
& NGP & 45989 & 49522 & 61893 & 72509 & 84882 & 99911 & 114929 & 130141 & 144286 & 32 \\
Objective Function & MCNGP & 47753 & 54825 & 58361 & 70730 & 88398 & 100793 & 115647 & 125546 & 144637 & 32 \\
& GP & 96019.55 & 581.75 & 320836 & 1124976 & 1931005 & 2688548 & 3510540 & 4296930 & 5054621 & 2 \\
& NGP & 40147.1 & 202.2 & 552902.2 & 1206541 & 1777132 & 2704061 & 3640260 & 4381432 & 5151602 & 1 \\
& MCNGP & 4.65 & 6.85 & 29499.45 & 200538.3 & 525486.9 & 808013.9 & 1166643 & 1382879 & 1840569 & 0 \\
\hline
\end{tabular}

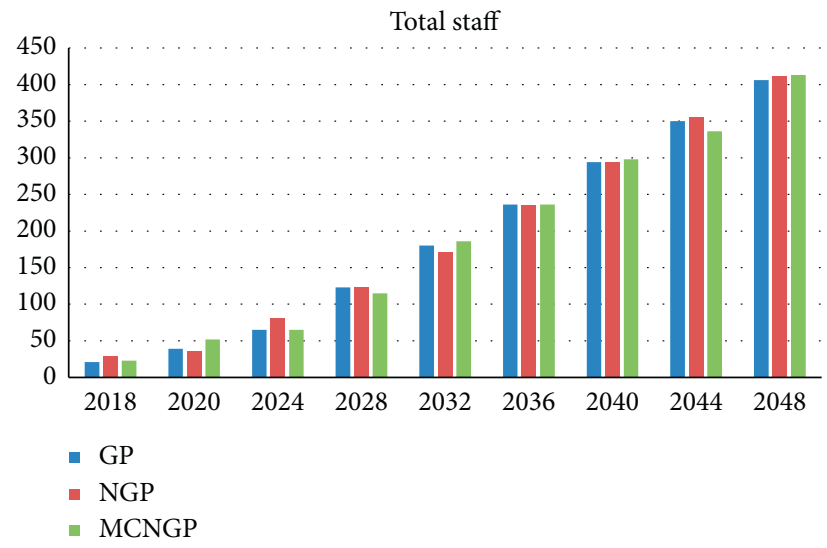

FIgURE 8: Comparison of staff growth between the proposed models.

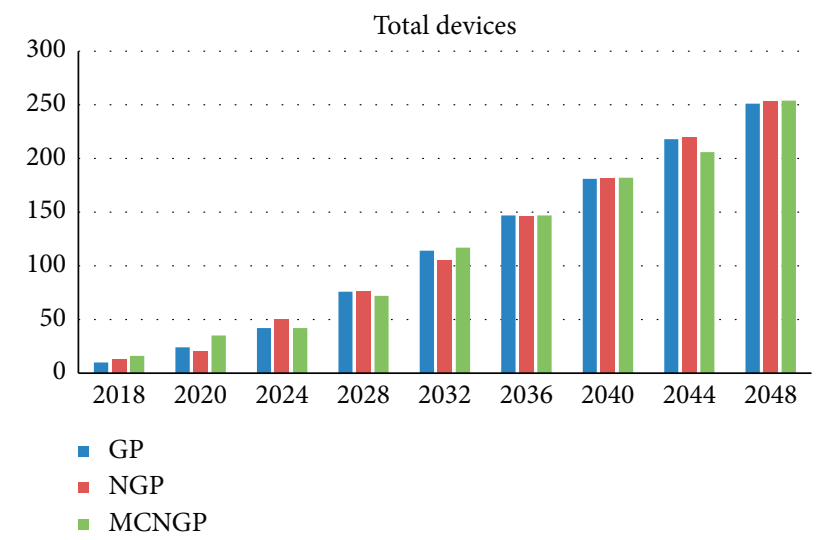

FIGURE 9: Comparison of increase in devices between the proposed models.

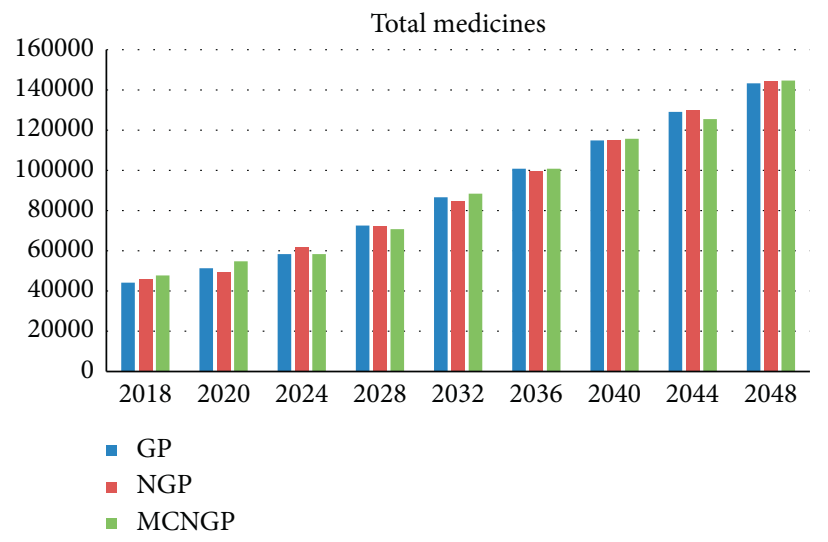

FIGURE 10: Comparison of the growing demand for medicines between the proposed models. 


\section{Conclusions}

In this paper, we proposed three models for solving healthcare planning problems. The proposed models were applied to a realistic case study of the Al-Amal Center for Oncology in Aden, Yemen. We used dynamic goal programming to predict the optimal solution for each variable in every period addressed in this article. Three models were eventually proposed: crisp, neutrosophic, and neutrosophic multi-choice goal programming. The goals addressed in the proposed models are related to the budget, the number of staffs and materials to perform the tasks efficiently. The proposed models yielded the optimum budget as well as the optimal number of staff and other medical supplies required to provide high-quality service for patients. Our results and insights thereof would be valuable for planners who could guide healthcare staff in providing the necessary resources for optimal annual planning. The diversity in the results obtained from the proposed models gives decision-makers the flexibility to make optimal decisions based on the state of the economy in each period. Although the proposed models were applied to healthcare planning, our approaches can be implemented on a large-scale healthcare system. Moreover, metaheuristics algorithms can be used to solve the models.

\section{Data Availability}

The data used to support the findings of this study are included within the article.

\section{Conflicts of Interest}

The authors declare that there are no conflicts of interest regarding the publication of this paper.

\section{Acknowledgments}

This work was supported by the Research Supporting Project Number (RSP-2021/389), King Saud University, Riyadh, Saudi Arabia.

\section{References}

[1] M. M. Arenas Parra, E. Lafuente Robledo, and M. V. Rodriguez Uria, "Goal programming model for evaluating hospital service performance," Advances in Multiple Objective and Goal Programming, , Springer, Berlin, Germany, 1997pp. 57-65, Lecture Notes in Economics and Mathematical Systems.

[2] D. A. Munoz, H. B. Nembhard, and K. Camargo, "A goal programming approach to address the proposal selection problem: a case study of a clinical and translational science institute," International Transactions in Operational Research, vol. 25, no. 1, pp. 405-423, 2018.

[3] J. T. Blake and M. W. Carter, "A goal programming approach to strategic resource allocation in acute care hospitals," European Journal of Operational Research, vol. 140, no. 3, pp. 541-561, 2002.

[4] A. K. Rifai and J. O. Pecenka, "An application of goal programming in healthcare planning," International Journal of
Operations \& Production Management, vol. 10, no. 3, pp. 28-37, 1990.

[5] N. K. Kwak and C. W. Lee, "Business process reengineering for health-care system using multicriteria mathematical programming," European Journal of Operational Research, vol. 140, no. 2, pp. 447-458, 2002.

[6] C. W. Lee and N. K. Kwak, "Information resource planning for a health-care system using an ahp-based goal programming method," Journal of the Operational Research Society, vol. 50, no. 12, pp. 1191-1198, 1999.

[7] E Grigoroudis and Y. A Phillis, "Modeling healthcare systemof-systems: a mathematical programming approach," IEEE Systems Journal, vol. 7, no. 4, pp. 571-580, 2013.

[8] C. W. Lee and N. K. Kwak, "Strategic enterprise resource planning in a health-care system using a multicriteria decision-making model," Journal of Medical Systems, vol. 35, no. 2, pp. 265-275, 2011.

[9] S. Turgay and H. Taşkın, "Fuzzy goal programming for healthcare organization," Computers \& Industrial Engineering, vol. 86, pp. 14-21, 2015.

[10] I. M. Hezam, M. Abdel-Baset, and F. Smarandache, "Neutrosophic goal programming," Neutrosophic Sets System, vol. 11, pp. 112-118, 2016.

[11] S. Islam and T. Kundu, "Neutrosophic goal geometric programming problem based on geometric mean method and its application," Neutrosophic Sets System, vol. 19, pp. 80-90, 2018.

[12] I. Maiti, T. Mandal, and S. Pramanik, "Neutrosophic goal programming strategy for multi-level multi-objective linear programming problem," Journal of Ambient Intelligence and Humanized Computing, vol. 11, no. 8, pp. 3175-3186, 2020.

[13] D. Sarma, A. Das, U. K. Bera, and I. M. Hezam, "Redistribution for cost minimization in disaster management under uncertainty with trapezoidal neutrosophic number," Computers in Industry, vol. 109, pp. 226-238, 2019.

[14] S. Dey, T. K. Roy, and T. K. Roy, "Neutrosophic goal programming technique and its application," International Journal of Computer \& Organization Trends, vol. 41, no. 1, pp. 6-13, 2017.

[15] S Pramanik and D Banerjee, "Neutrosophic number goal programming for multi-objective linear programming problem in neutrosophic number environment," MOJ Current Research \& Reviews, vol. 1, no. 3, pp. 135-141, 2018.

[16] A. Al-Quran and N. Hassan, Goal Programming View project Data Envelopment Analysis View project SEE PROFILE Neutrosophic Vague Soft Set and its Applications, vol. 11, no. 2, pp. 141-163, 2017.

[17] I. M. Hezam, M. K. Nayeem, A. Foul, and A. F. Alrasheedi, "COVID-19 Vaccine: a neutrosophic MCDM approach for determining the priority groups," Results in Physics, vol. 20, Article ID 103654, 2021.

[18] I. M. Hezam, “COVID-19 Global Humanitarian Response Plan: an optimal distribution model for high-priority countries," ISA Transactions, 2021.

[19] R. Caballero, T. Gómez, M. González, L. Rey, and F. Ruiz, "Goal programming with dynamic goals," Journal of MultiCriteria Decision Analysis, vol. 7, no. 4, pp. 217-229, 1998.

[20] T. Trzaskalik, "Dynamic goal programming models," Advances in Multiple Objective and Goal Programming, Springer, Berlin, Germany, 1997pp. 111-119, Lecture Notes in Economics and Mathematical Systems.

[21] I. Jridi, B. Jerbi, B. Jerbi, and H. Kamoun, "Menu planning with a dynamic goal programming approach," Multiple Criteria Decision Making, vol. 13, pp. 74-87, 2018. 
[22] C.-T. Chang, "Multi-choice goal programming," Omega, vol. 35, no. 4, pp. 389-396, 2007.

[23] L. A. Zadeh, "Fuzzy sets," Information and Control, vol. 8, no. 3, pp. 338-353, 1965.

[24] K. T. Atanassov, "Intuitionistic fuzzy sets," Fuzzy Sets and Systems, vol. 20, no. 1, pp. 87-96, 1986.

[25] F. Smarandache, A Unifying Field in Logics: Neutrosophic Logic, Neutrosophic Set, Neutrosophic Probability and Statisticspp. 1-141, American Research Press, Santa Fe, NM, USA, 4th edition, 1999. 